\title{
The isotopic composition of precipitation from a winter storm - a case study with the limited-area model COSMO $\mathrm{C}_{\text {iso }}$
}

\author{
S. Pfahl ${ }^{1}$, H. Wernli ${ }^{1}$, and K. Yoshimura ${ }^{2}$ \\ ${ }^{1}$ Institute for Atmospheric and Climate Science, ETH Zurich, 8092 Zurich, Switzerland \\ ${ }^{2}$ Atmosphere and Ocean Research Institute, University of Tokyo, Tokyo, Japan \\ Correspondence to: S. Pfahl (stephan.pfahl@env.ethz.ch) \\ Received: 19 August 2011 - Published in Atmos. Chem. Phys. Discuss.: 22 September 2011 \\ Revised: 18 January 2012 - Accepted: 6 February 2012 - Published: 14 February 2012
}

\begin{abstract}
Stable water isotopes are valuable tracers of the atmospheric water cycle, and potentially provide useful information also on weather-related processes. In order to further explore this potential, the water isotopes $\mathrm{H}_{2}^{18} \mathrm{O}$ and $\mathrm{HDO}$ are incorporated into the limited-area model COSMO. In a first case study, the new $\mathrm{COSMO}_{\text {iso }}$ model is used for simulating a winter storm event in January 1986 over the eastern United States associated with intense frontal precipitation. The modelled isotope ratios in precipitation and water vapour are compared to spatially distributed $\delta^{18} \mathrm{O}$ observations. $\mathrm{COSMO}_{\text {iso }}$ very accurately reproduces the statistical distribution of $\delta^{18} \mathrm{O}$ in precipitation, and also the synopticscale spatial pattern and temporal evolution agree well with the measurements. Perpendicular to the front that triggers most of the rainfall during the event, the model simulates a gradient in the isotopic composition of the precipitation, with high $\delta^{18} \mathrm{O}$ values in the warm air and lower values in the cold sector behind the front. This spatial pattern is created through an interplay of large scale air mass advection, removal of heavy isotopes by precipitation at the front and microphysical interactions between rain drops and water vapour beneath the cloud base. This investigation illustrates the usefulness of high resolution, event-based model simulations for understanding the complex processes that cause synoptic-scale variability of the isotopic composition of atmospheric waters. In future research, this will be particularly beneficial in combination with laser spectrometric isotope observations with high temporal resolution.
\end{abstract}

\section{Introduction}

Stable water isotopes are useful tracers of processes in the global water cycle and are widely applied for, e.g., hydrological and paleo-climatological studies (Gat, 1996). For instance, isotope data from ice cores can be used as a proxy for reconstructing long-term temperature changes (Dansgaard et al., 1993). Also on short, hourly to daily time scales, the isotopic composition of atmospheric waters and precipitation is subject to strong variability (e.g., Rindsberger et al., 1990; Wen et al., 2010) and potentially provides valuable information on moisture sources, water transport and cloud microphysics (Lawrence et al., 1982; Smith, 1992; Gedzelman and Arnold, 1994; Pfahl and Wernli, 2008). However, this potential has not yet been fully explored, mostly owing to the complexity of the involved dynamical and microphysical processes and the sparsity of isotope observations with high temporal resolution. More recently, more such data have become available based on new spectrometric measurement techniques, both from in-situ and remote sensing observations (e.g., Sturm and Knohl, 2010; Wen et al., 2010; Schneider et al., 2010). In order to improve our understanding of the mechanisms driving isotope variations in these measurements, but also in other observations on longer time scales, numerical models are commonly applied. The most comprehensive way of simulating all important processes is to incorporate water isotopes into general circulation models (GCMs) of the atmosphere (e.g., Joussaume et al., 1984; Hoffmann et al., 1998; Yoshimura et al., 2008; Risi et al., 2010b). Global models, due to their relatively coarse spatial resolution, are less well suited for exploring 
synoptic-scale isotopic variability, associated e.g. with the passage of frontal or convective systems. Therefore, isotope physics have also been implemented in limited-area models. Sturm et al. (2005) incorporated water isotopes into the regional climate model REMO, which was subsequently used for investigations on long, climatological time scales (e.g., Sturm et al., 2007). Smith et al. (2006) and Blossey et al. (2010) used cloud resolving models for simulating idealised tropical circulations, focusing on isotope variations in the tropical tropopause layer. Yoshimura et al. (2010) simulated the isotopic content of precipitation from an atmospheric river event at the US west coast with the model IsoRSM and compared the results from this case study to observations by Coplen et al. (2008). So far, all these regional models have either been used in an idealised setup or have relatively simple cloud microphysics and hydrostatic numerics, comparable to those used in GCMs. The latter implies limitations with respect to the accuracy of simulations of mesoscale atmospheric features.

In this study, the stable water isotopes $\mathrm{H}_{2}^{18} \mathrm{O}$ and $\mathrm{HDO}$ are incorporated into the non-hydrostatic COSMO model (Steppeler et al., 2003), a limited-area weather forecast and climate model that is operationally used at several European weather services and thus continuously improved with respect to its numerics and physical parameterisations. In order to test this new isotope-enabled model, hindcast simulations of a winter storm event are performed. Such a setup, in which the regional model is run over a few days, driven by reanalysis data and an isotope GCM, has the advantage that the simulated meteorological and water isotope fields can be directly evaluated by comparing with measurements in an event-based manner (cf. Yoshimura et al., 2010).

One of the very few cases for which spatially distributed isotope measurements were performed with a high temporal resolution is a winter storm that hit the eastern United States in January 1986. Gedzelman and Lawrence (1990) (in the following referred to as GL90) collected the precipitation at more than 20 stations (see Fig. 1) between 06:00 UTC 18 January 1986 and 06:00 UTC 21 January 1986 with mostly three-hourly, at some stations six-hourly time resolution. The $\delta^{18} \mathrm{O}$ content of this precipitation was then analysed in a mass spectrometer. Moreover, $\delta^{18} \mathrm{O}$ samples were obtained from water vapour at Raleigh-Durham, North Carolina (abbreviated RDU, see again Fig. 1) and from several snow cores from West Virginia (see GL90 for a map of the locations). No analysis of deuterium was performed. GL90 investigated these isotope data using meteorological charts, satellite data and simple, one dimensional model calculations. They found that the height of precipitation formation, interactions between rain and water vapour beneath the cloud base and, to a lesser extent, the convective or stratiform character of the precipitation were important for determining the isotope ratios.

In the present study, on the one hand the data gathered by GL90 are used for evaluating the new regional isotope

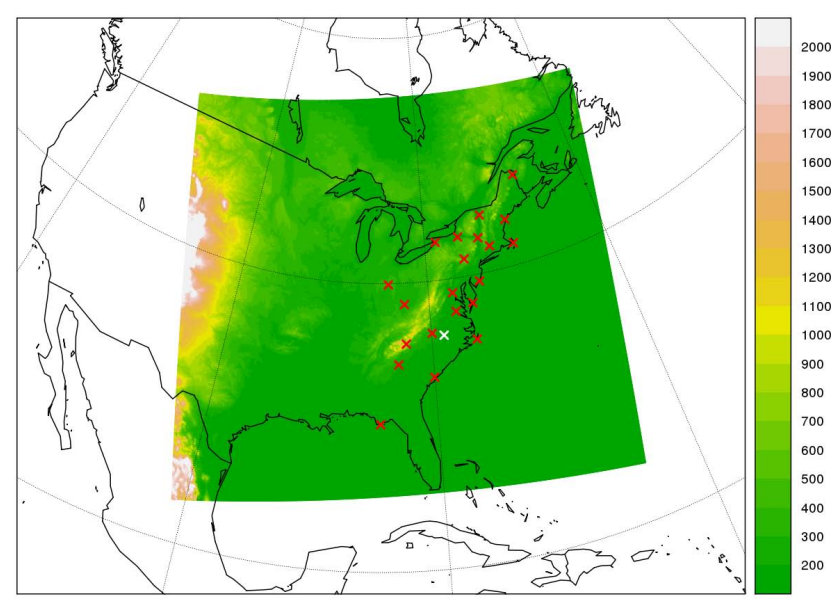

Fig. 1. $\mathrm{COSMO}_{\text {iso }}$ model domain and topography (colours, in metres a.s.1.). Red crosses show the locations of measurement stations where $\delta^{18} \mathrm{O}$ in precipitation was analysed by GL90. The white cross denotes the location of the station RDU where vapour isotopes were sampled.

model. On the other hand, the results from the simulation are applied to obtain a more complete picture of the spatial and temporal variability of the water isotopes. Furthermore, the model is used for investigating the mechanisms leading to the observed synoptic-scale isotope variability, also with the help of a sensitivity experiment. It is the overall aim of this research to better understand these mechanisms and, by this, further explore the potential of water isotopes as tracers of weather-related processes.

In Sect. 2, the new regional water isotope model will be introduced and some details on isotope parameterisations will be given. Furthermore, the simulation setup used in this study will be described. In Sect. 3.1 results of the simulation will be presented and compared to observations by GL90. Processes related to isotopic variations in the simulated precipitation will be investigated in more detail in Sect. 3.2. Section 3.3 will then briefly discuss the temperature effect in the model. Finally, Sect. 4 will summarise the most important findings and outline opportunities for future research.

\section{Model description}

\subsection{COSMO}

The COSMO model (Steppeler et al., 2003) is a nonhydrostatic limited-area model, which is used for operational weather forecasting at several European weather services, including the German and Swiss weather services. It is based on the primitive fluid-dynamical equations and can be used for simulations with horizontal resolutions of $50 \mathrm{~km}$ down to less than $1 \mathrm{~km}$. The model includes two separate time integration schemes and several different parameterisations 
for, e.g., cloud microphysics and moist convection. Operationally, the German weather service uses two model setups, the first one with a horizontal grid spacing of $7 \mathrm{~km}$, including a parameterisation of deep convection, and the second one with a grid spacing of $2.8 \mathrm{~km}$ and without parameterising deep convection. In addition to short-range forecasts, the COSMO model can also be used for regional climate simulations (e.g., Jacob et al., 2007).

\subsection{Water isotope implementation}

In order to extend the COSMO model for simulating stable isotopes in the atmospheric water cycle, an approach is adopted similar to previous implementations of isotopes in GCMs and regional models (see again Joussaume et al., 1984; Sturm et al., 2005; Blossey et al., 2010, for examples). A parallel water cycle is introduced that does not affect other model components and is used as a purely diagnostic tool. All prognostic moisture fields, which are simulated by the model in terms of specific humidities, are duplicated twice, representing the specific humidities of $\mathrm{H}_{2}^{18} \mathrm{O}$ and HDO, respectively. From these prognostic specific humidity fields, the isotope ratios in usual $\delta$-notation can be calculated. The implementation is made for a one-moment microphysical scheme with 5 species, namely water vapour, cloud water, cloud ice, rain and snow (for details, see Doms et al., 2005), leading to 10 additional prognostic variables for the heavy isotopes. These additional moisture fields are affected by the same physical processes as the original humidity, e.g., they are transported by large scale winds and are involved in the formation of clouds and precipitation. Only during phase transitions do they behave differently than the standard light water owing to isotopic fractionation. In the following subsections, some details on the transport and microphysical parameterisations of the heavy isotopes will be given.

\subsubsection{Transport}

There are three major mechanisms in the COSMO model that transport moisture in space: moist convection (which will be treated in Sect. 2.2.4), grid-scale advection and boundary layer turbulence. The latter only affects the vertical transport of water vapour and non-precipitating hydrometeors, i.e., turbulent transport is neglected for rain and snow. For the heavy isotopes, the same flux-gradient parameterisation and the same exchange coefficients as for the light water are used. In this way, all isotopes are transported independently of each other.

For the three-dimensional advection of moisture quantities, the Bott advection scheme (Bott, 1989) with fourth order accuracy is applied in our setup. This scheme is positive definite and mass-conserving ${ }^{1}$. For the advection of different

\footnotetext{
${ }^{1}$ Note, however, that the implementation of the scheme in the current version of the COSMO model does not fully retain this mass
}

isotope species it is most important that no fractionation occurs, i.e., that the ratios between two isotopes do not change during adiabatic and frictionless advection. This cannot be guaranteed if the isotope humidities (or, more generally, two arbitrary tracers) are transported independently of each other (Schär and Smolarkiewicz, 1996; Risi et al., 2010b), mostly owing to numerical errors and non-linearities in the advection scheme. Therefore, for the transport of heavy isotopes a modified scheme is implemented that employs isotope ratios, instead of specific humidities, for estimating the advective fluxes, similar to the approach of Risi et al. (2010b). Details of this scheme and a one-dimensional test are described in Appendix A.

\subsubsection{Surface fluxes}

Surface fluxes of heavy isotopes over the ocean are parameterised using a Craig-Gordon type model (Craig and Gordon, 1965). Two options for the non-equilibrium fractionation factor are implemented: The first one, which is commonly applied in many isotope models, parameterises the fractionation factor as a function of wind velocity, following Merlivat and Jouzel (1979). The second one uses a wind-speed independent formulation based on the empirical results of Pfahl and Wernli (2009). The second option is chosen for the reference simulation in the present study. To test the impact of this choice, a simulation using the parameterisation by Merlivat and Jouzel (1979) is also performed. Since the simulated $\delta^{18} \mathrm{O}$ fields from this experiment are very similar to the results of the reference simulation, they will not be shown in detail in the following. In order to evaluate the difference between the two parameterisations, observations of deuterium excess would be required, which are not available for the storm investigated here. For the isotopic composition of the ocean, a constant, slightly enriched value of $\delta^{18} \mathrm{O}=1 \%$ o is used, roughly corresponding to average surface waters in the western North Atlantic (LeGrande and Schmidt, 2006). Evapotranspiration from land surfaces is assumed not to fractionate, similar to most isotope models (e.g., Hoffmann et al., 1998; Yoshimura et al., 2008; Risi et al., 2010b). In future work, water isotopes will also be incorporated into the land surface scheme of the COSMO model, involving a more complete parameterisation of isotope fluxes from land surfaces. The isotopic composition of the soil water is adopted from the IsoGSM model (Yoshimura et al., 2008, see also Sect. 2.2.5).

\subsubsection{Cloud microphysics}

In the microphysical scheme, transfer rates between the different water species during the formation of clouds and precipitation are specified. For example, the transfer rate $S_{\mathrm{au}}$ of

conservation. This issue is not crucial for the water isotope simulations and will be addressed in an upcoming publication. 
cloud water $q_{\mathrm{c}}$ to form rain $q_{\mathrm{r}}$ by autoconversion is then part of the tendency equations of the specific humidities:

$$
\begin{aligned}
& \frac{\partial q_{\mathrm{c}}}{\partial t}=\ldots-S_{\mathrm{au}}+\ldots \\
& \frac{\partial q_{\mathrm{r}}}{\partial t}=\ldots+S_{\mathrm{au}}+\ldots
\end{aligned}
$$

Since a one-moment scheme is used, specific humidities are the only prognostic variables, and information about the sizes of the different particles is only implicitly taken into account. The isotopic composition of the particles is assumed to be independent of their size. For all microphysical interactions that do not involve the vapour phase (e.g., autoconversion of cloud particles to form rain or freezing of liquid water), there is no isotopic fractionation, and the transfer rates ${ }^{\mathrm{h}} S$ of the heavy isotopes, following Blossey et al. (2010), are given by

${ }^{\mathrm{h}} S=\frac{{ }^{\mathrm{h}} q_{\mathrm{s}}}{{ }^{1} q_{\mathrm{s}}} \cdot{ }^{1} S$,

where ${ }^{\mathrm{h}} q_{\mathrm{s}}$ and ${ }^{1} q_{\mathrm{s}}$ are the specific humidities of heavy and light isotopes, respectively, in the source phase and ${ }^{1} S$ is the transfer rate of the standard light isotope ${ }^{2}$.

During phase transitions involving water vapour, isotopic fractionation occurs. For its parameterisation, equilibrium fractionation factors $\alpha_{\mathrm{e}}$ with respect to liquid water and ice are calculated following Majoube (1971) and Merlivat and Nief (1967), respectively. Here, these fractionation factors are defined to give the ratio between the isotopic composition of vapour and the condensed phase, i.e., they are smaller than 1. Molecular diffusivities from measurements by Merlivat (1978) are applied. In the COSMO model, condensation and evaporation of cloud water are parameterised with the help of a saturation adjustment technique, implying thermodynamic equilibrium between vapour and liquid clouds. Also for the heavy isotopes, an equilibrium approach can be adopted, since the equilibration time with respect to small droplets typically is in the order of seconds (see again Blossey et al., 2010). This leads to a diagnostic equation for the isotope ratio in cloud water, as given by Blossey et al. (2010) in their Eq. (B21).

For rain drops, owing to their larger size, the assumption of isotopic equilibrium is not valid, and the mass transfer between the drop and the surrounding vapour has to be modelled in an explicit way. This affects the total moisture budget of the drop only beneath the cloud base, where the rain falls into unsaturated air and starts evaporating. The isotopic content of the rain, however, may also change within the cloud. In COSMO, the transfer rate due to rain evaporation is parameterised by

${ }^{1} S_{\mathrm{ev}}=F\left({ }^{1} q_{\mathrm{r}}\right)\left(q_{1}^{\star}-{ }^{1} q_{\mathrm{v}}\right)$,

\footnotetext{
${ }^{2}$ Note that in the following, the superscript 1 will always be used for the light isotope $\mathrm{H}_{2}^{16} \mathrm{O}$, which is equivalent to the total simulated moisture, i.e., the standard COSMO specific humidity, in very good approximation.
}

where $q_{1}^{\star}$ denotes the saturation humidity with respect to liquid water, and $q_{\mathrm{v}}$ and $q_{\mathrm{r}}$ are the specific humidities of water vapour and rain, respectively. The function $F$ depends, in addition to the rain content $q_{\mathrm{r}}$, also on water diffusivity. However, in COSMO this dependence is not explicitly taken into account, but rather included in a semi-empirical constant. Because of this, the heavy isotopes are not implemented directly via their diffusivities here (this would imply a change also in the standard transfer rate), but a semi-empirical approach is used based on a study by Stewart (1975). In future research, it may be tested how this implementation compares with a more theoretical strategy as employed, e.g., by Blossey et al. (2010). Following Stewart (1975), the heavy isotope mass exchange rate $d^{\mathrm{h}} m / d t$ between a rain drop and the surrounding vapour is related to the total mass exchange rate $d^{1} m / d t$ by

$\frac{d^{\mathrm{h}} m}{d t}=\frac{d^{1} m}{d t}\left(\frac{{ }^{\mathrm{h}} D}{{ }^{1} D}\right)^{n} \frac{\alpha_{\mathrm{e}} q_{1}^{\star}{ }^{\mathrm{h}} q_{\mathrm{r}} /{ }^{1} q_{\mathrm{r}}-{ }^{\mathrm{h}} q_{\mathrm{v}}}{q_{1}^{\star}-{ }^{1} q_{\mathrm{v}}}$.

The rightmost fraction contains the humidity gradients of heavy (numerator) and light (denominator) isotopes between drop surface and the surrounding vapour. ${ }^{\mathrm{h}} D$ and ${ }^{1} D$ are the diffusivities of heavy and light isotopes, respectively. Based on the measurements by Stewart (1975), the exponent $n$ is chosen to be 0.58 , independent of the drop size (see also Bony et al., 2008). Combining Eqs. (3) and (4), one obtains the heavy isotope transfer rate for rain evaporation and equilibration with the surrounding vapour:

${ }^{\mathrm{h}} S_{\text {eveq }}=F\left({ }^{1} q_{\mathrm{r}}\right)\left(\frac{{ }^{\mathrm{h}} D}{{ }^{1} D}\right)^{n}\left(\alpha_{\mathrm{e}} q_{1}^{\star} \frac{{ }^{\mathrm{h}} q_{\mathrm{r}}}{{ }^{1} q_{\mathrm{r}}}-{ }^{\mathrm{h}} q_{\mathrm{v}}\right)$.

In the case of rain falling through clouds, there is no evaporation and the transfer rate ${ }^{1} S_{\mathrm{ev}}$ specified in Eq. (3) vanishes. Nevertheless, Eq. (5) shows that there may be a nonvanishing transfer of heavy isotopes also in this case if rain and vapour are not in isotopic equilibrium.

The parameterisation of isotopic fractionation during the interaction of vapour and the ice phase follows Jouzel and Merlivat (1984). It is assumed that, due to the low diffusivities of water molecules within the ice, there is no homogenisation of isotopes in the ice particles. During deposition, the water vapour interacts only with the outermost layer of the particles, whose isotopic composition is assumed to be equal to the isotopic composition of the deposition flux. In addition to equilibrium fractionation, kinetic effects occur if the air is super-saturated with respect to ice. This is parameterised using a combined fractionation factor given by Jouzel and Merlivat (1984) in their Eq. (14) (which is equivalent to Eq. (B26) of Blossey et al., 2010). The ratio of the ventilation factors of light and heavy isotopes, ${ }^{1} f /{ }^{\mathrm{h}} f$, which is needed in this equation, is set to 1 for deposition on small ice crystals and to 0.995 for deposition on snow flakes. The latter is a typical value for particles between 0.5 and $1 \mathrm{~mm}$ in length 
(see again Jouzel and Merlivat, 1984). An advantage of the COSMO microphysical scheme compared to other models is that the supersaturation is predicted in a prognostic way. No saturation adjustment is used over ice (in contrast, e.g., to the model of Blossey et al., 2010), and there is no need for prescribing supersaturation as a function of temperature (cf. Jouzel and Merlivat, 1984; Hoffmann et al., 1998; Risi et al., 2010b). The sublimation of ice and snow particles is assumed to occur without isotopic fractionation, and since no information is available about the layering of single particles, the average isotope composition of ice or snow is used for the sublimation flux (see again Bony et al., 2008; Blossey et al., 2010).

\subsubsection{Moist convection}

For the parameterisation of moist convection, a modified version of the Tiedtke mass flux scheme (Tiedtke, 1989) is applied in the COSMO model (see again Doms et al., 2005, for details). In order to implement heavy isotopes in this parameterisation, the humidity variables are duplicated, as described above. All physical processes during simulated convective up- and downdrafts affect the heavy isotopes in a similar way as the standard light humidity. Also the closure assumptions, e.g., the entrainment and detrainment rates, are treated similarly. Only during phase transitions, isotopic fractionation occurs. The relatively simple bulk cloud model in the convection scheme uses saturation adjustment for parameterising the formation of both liquid water and ice. For the former, isotopic fractionation is parameterised using an equilibrium approach, as described in Sect. 2.2.3. With respect to ice, kinetic fractionation is taken into account following Jouzel and Merlivat (1984). Here, the supersaturation is prescribed as a function of temperature, with the tuning parameter $\lambda$ set to 0.004 (Risi et al., 2010b). In a temperature range between $-23^{\circ} \mathrm{C}$ and $0{ }^{\circ} \mathrm{C}$, clouds are supposed to consist of both liquid and ice particles (consistent with the standard treatment in the COSMO convection scheme), and the isotopic composition of the condensate is interpolated between the two phases, assuming a quadratic increase of the liquid water fraction with temperature (note that in this case, the diagnostic relationship for the isotopic composition of cloud water is replaced by a closed system approach, similar to Bony et al., 2008).

In the Tiedtke scheme, saturation in the convective downdrafts is assumed to be maintained by evaporation of falling precipitation. The isotopic composition of the evaporate from liquid precipitation is calculated using a closed model with isotopic equilibrium (since the relative humidity is always $100 \%$ ). Beneath the cloud base, in unsaturated conditions, the evaporation rate of rain is parameterised following Kessler (1969). For the heavy isotopes, this liquid evaporation rate is scaled according to Eq. (4), again incorporating kinetic effects based on measurements by Stewart (1975). No fractionation occurs during the sublimation of solid precipi- tation (see again Sect. 2.2.3), and in the mixed phase range interpolation is used. The isotopic composition of the precipitation is obtained from the vertically integrated precipitation fluxes, as no prognostic information on the rain or snow water content on a specific level is available in the scheme.

\subsubsection{Initial and boundary data}

Since COSMO is a regional model, boundary data have to be provided for all prognostic variables. In this study, ERA40 reanalyses (Uppala et al., 2005) from the European Centre for Medium-Range Weather Forecasts (ECMWF) are used as boundary and initial conditions for the standard model variables. These data are available every six hours with a spectral resolution of T159 and 60 vertical levels and are interpolated to the COSMO grid (see Sect. 2.3). After the model initialisation, information from the ERA40 data is only used at and close to the model boundaries, employing a relaxation scheme following Davies (1976). No nudging of the COSMO fields is performed in the interior of the model domain. For the water isotopes, initial and boundary data are taken from a historical isotope GCM simulation by Yoshimura et al. (2008), who employed the IsoGSM global model with the atmospheric circulation constrained to reanalysis data with the help of a nudging technique. Isotope data from other GCM simulations could also be applied in future research. Isotope ratios in water vapour with a spectral resolution of T62 and on 17 vertical levels are obtained from the IsoGSM simulations. The isotope data are transferred to the COSMO model grid in the same way as the ERA40 humidity fields using linear interpolation. Since IsoGSM does not simulate hydrometeors in a prognostic way, boundary data for isotope ratios in cloud water and ice are calculated from the isotope ratios in vapour by assuming isotopic equilibrium with respect to liquid water and ice, respectively. The boundary relaxation of the water isotope data is done based on isotope ratios instead of specific humidities, since this leads to more stable results. For the three-dimensional rain and snow fields, no boundary data are provided by ERA40. A no-flux boundary condition is used for these variables and the corresponding heavy isotopes.

\subsection{Simulation setup}

In the following, the COSMO model with the water isotope implementation will be named $\mathrm{COSMO}_{\text {iso. }}$. In this study, the new model, based on COSMO version 4.11, is applied for hindcast simulations with an integration time of $126 \mathrm{~h}$. A horizontal grid spacing of $0.0625^{\circ}$ (in a rotated grid), corresponding to approximately $7 \mathrm{~km}$, and 40 hybrid vertical levels are used. For the time integration, a third order RungeKutta scheme is applied. The model domain covers the eastern United States, parts of Canada and the western North Atlantic, as shown in Fig. 1. The simulation starts at 00:00 UTC 16 January 1986 and runs until 06:00 UTC 21 January 1986. 

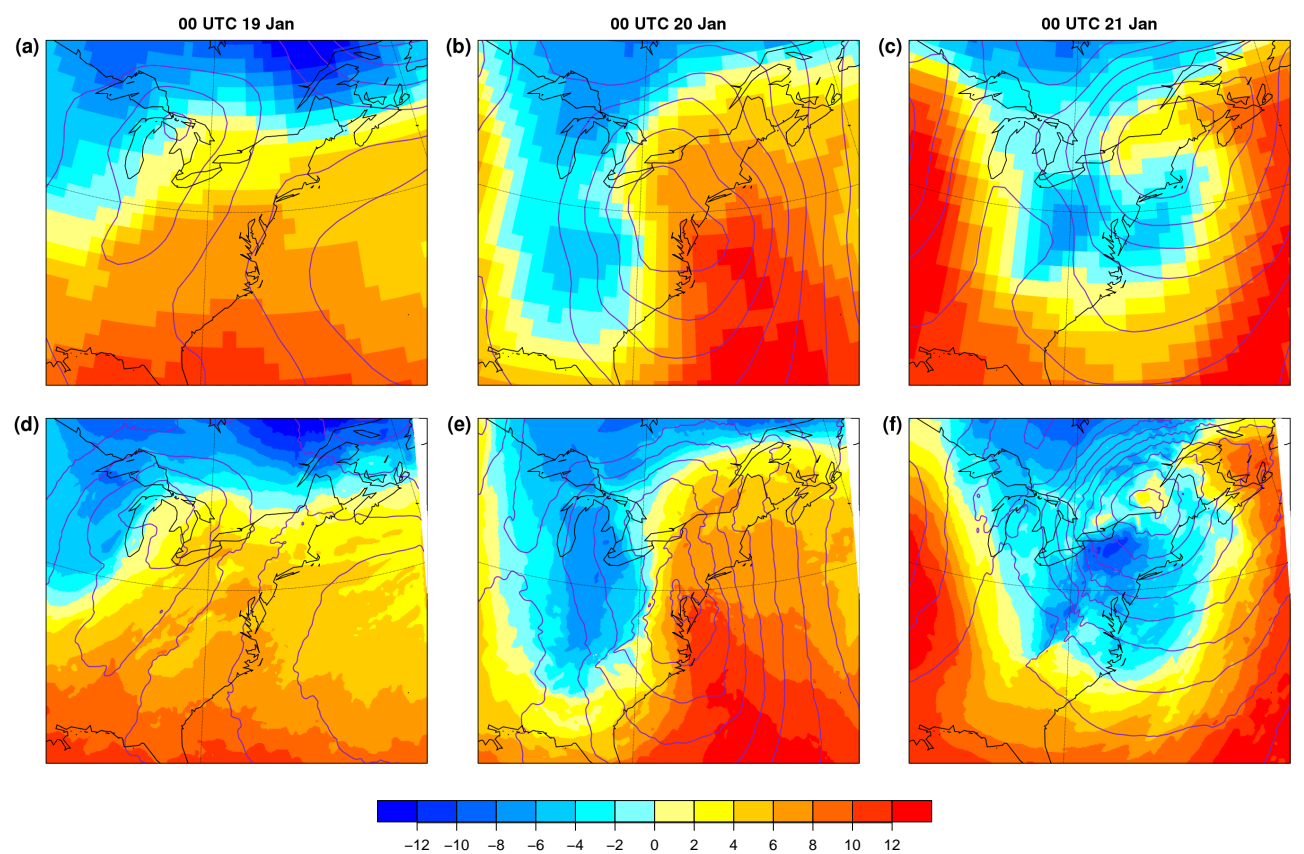

Fig. 2. Temperature on $850 \mathrm{hPa}$ (colours, in ${ }^{\circ} \mathrm{C}$ ) and sea level pressure (purple contours, contour interval $\left.4 \mathrm{hPa}\right)$ at (a, d) 00:00 UTC 19 January, (b, e) 00:00 UTC 20 January and (c, f) 00:00 UTC 21 January from ERA40 reanalyses (a-c) and the COSMO iso simulation (d-f).

Model output will be analysed for the period 06:00 UTC 18 January to 06:00 UTC 21 January, i.e., the last three days of the model integration. During this time, a winter storm developed over the eastern US and the $\delta^{18} \mathrm{O}$ content of the precipitation at several stations was measured by GL90 (see Sect. 1).

In addition to the reference simulation with isotope physics parameterised as described in Sect. 2.2, a sensitivity experiment is performed. In this experiment, isotopic fractionation during the interaction of rain and water vapour is switched off, such that no equilibration of the falling rain droplets occurs and the isotope ratio of the vapour evaporating from rain drops is equal to the composition of the rain. In the next section, results from the reference simulation and this sensitivity experiment will be presented.

\section{Results and discussion}

\subsection{Model evaluation}

\subsubsection{Meteorology}

In order to be able to reasonably simulate isotopic variations in atmospheric waters in comparison with event-based observations, first of all the meteorological conditions simulated by $\mathrm{COSMO}_{\text {iso }}$ should be realistic. For the winter storm event modelled here, this is checked by comparing $\mathrm{COSMO}_{\text {iso }}$ results with ERA40 reanalyses. Figure 2 shows the temperature on $850 \mathrm{hPa}$ and the sea level pressure (SLP) from both model and reanalysis at 00:00 UTC on the last three days of the simulation period. A region covering the central part of the model domain is shown, which will be the same for all horizontal maps in the following. At 00:00 UTC 19 January (Fig. 2a), the temperature structure over the US and the western North Atlantic is relatively zonal. Only in the north-west of the displayed region, south of the Great Lakes, colder air masses spread southward, coinciding with a shallow, meridionally extended low pressure anomaly. During the following day, this colder air moves in south-eastward direction, the horizontal temperature gradient becomes more pronounced, and the low pressure system slightly intensifies. At 00:00 UTC 20 January (Fig. 2b), it is located over the US east coast, and an elongated front separates the cold air masses over the interior of the continent from the warmer coastal and maritime air. Subsequently, the low pressure system moves north-eastwards and further intensifies, reaching central pressure values below $992 \mathrm{hPa}$. At 00:00 UTC on the following day, its centre reaches New England and the Canadian border (Fig. 2c). The cold sector of the cyclone at this date covers the north-east of the United States and parts of the western North Atlantic. This synoptic evolution is properly represented by $\mathrm{COSMO}_{\text {iso }}$ (Fig. 2d-f). The most pronounced differences to the ERA40 data occur after 5 days of the simulation (cf. Fig. 2c, f), when the low pressure anomaly simulated by $\mathrm{COSMO}_{\text {iso }}$ is stronger than in the reanalysis data. This may be partly due to the much finer spatial resolution. Furthermore, the temperature close to the cyclone centre is underestimated by the model. Apart from this, temperature 

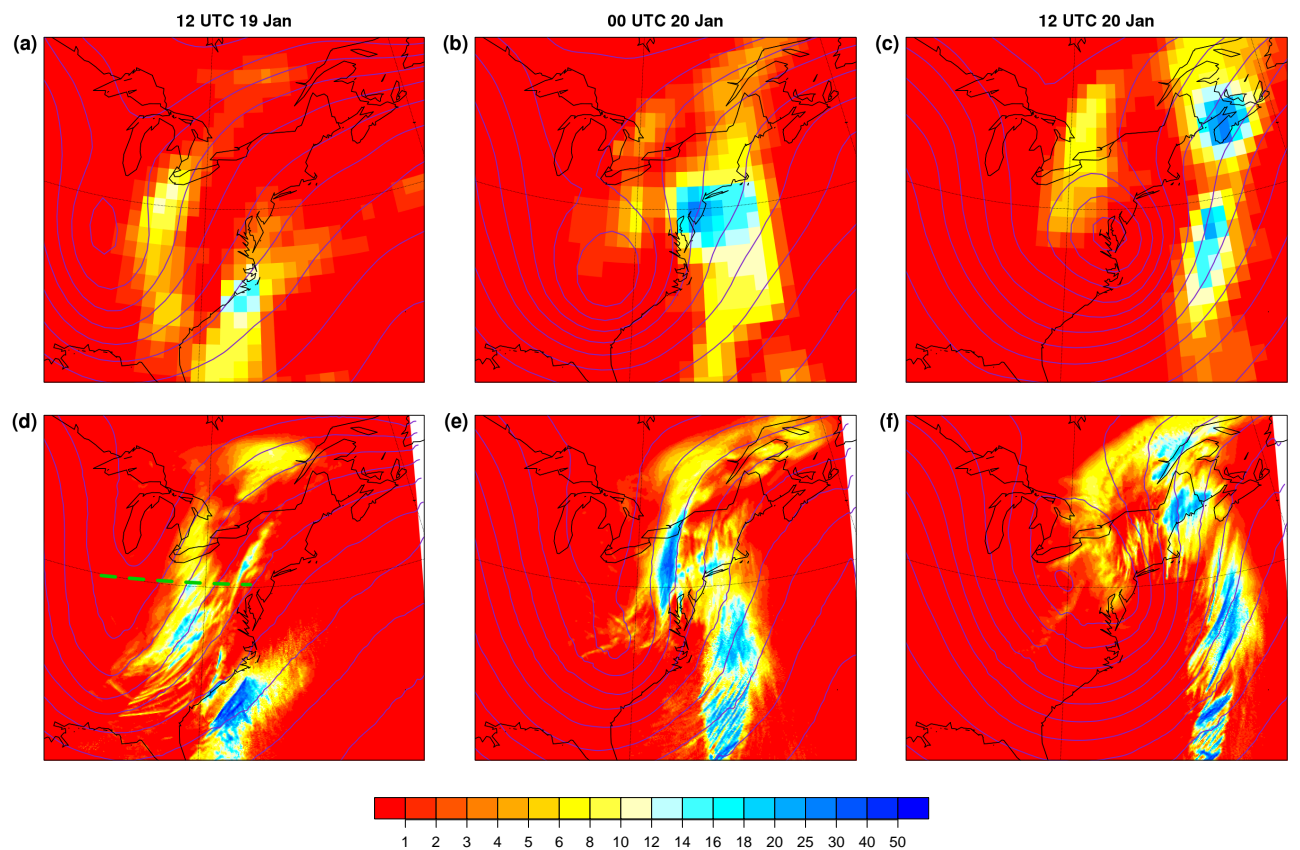

Fig. 3. Six-hourly accumulated surface precipitation (colours, in $\mathrm{mm}$ ) and geopotential height on $500 \mathrm{hPa}$ (purple contours, contour interval $50 \mathrm{~m})$ at (a, d) 12:00 UTC 19 January, (b, e) 00:00 UTC 20 January and (c, f) 12:00 UTC 20 January. Precipitation is accumulated from $3 \mathrm{~h}$ before to three hours after the respective dates. In panels $(\mathbf{a}-\mathbf{c})$, ERA40 reanalysis data are shown, in $(\mathbf{d}-\mathbf{f})$ results from the COSMO simulation. The green dashed line in panel (d) indicates the position of the vertical cross section shown in Figs. 10 and 11.

and SLP differences between the two datasets are mostly minor and restricted to regional scales.

In Fig. 3, geopotential height on $500 \mathrm{hPa}$ and precipitation from ERA40 and COSMO ${ }_{\text {iso }}$ are shown. Note that the dates differ from those in Fig. 2; here, data at 12:00 UTC 19 January, 00:00 UTC 20 January and 12:00 UTC 20 January are displayed, owing to the availability of isotope observations at this dates (see below). Precipitation is accumulated over a six-hourly period comprising the respective dates. The ERA40 precipitation has been obtained from short-term forecasts of the ECMWF model, considering forecast steps from 9 to $15 \mathrm{~h}$. The geopotential height contours in Fig. 3 show a pronounced upper level trough moving in eastward direction, which induces the advection of cold air described above. The formation and intensification of a cutoff to the west of the surface low is less pronounced in the $\mathrm{COSMO}_{\text {iso }}$ simulation compared to the ERA40 data. Both the ECMWF model and $\mathrm{COSMO}_{\text {iso }}$ simulate precipitation over the continent mostly along the cold front of the cyclone and in the region of the band-back warm front, close to the centre of the low pressure system. In the COSMO iso results, the main continental precipitation band is shifted to the east compared to the ECMWF forecast, and in particular at 00:00 UTC 20 January (Fig. 3b, e), the precipitation intensity within this band is larger. Moreover, there is more rainfall in the warm sector, especially at 12:00 UTC 19 January. Of course, the spatial variability in the $\mathrm{COSMO}_{\text {iso }}$ fields is much larger, owing to the smaller grid spacing. Nevertheless, most of the conti- nental precipitation in $\mathrm{COSMO}_{\text {iso }}$ is of large-scale character, only in the southern parts close to the coast there are some contributions from the convection scheme. Hence, the influence of this scheme (whose microphysical parameterisations are relatively simple, cf. Sect. 2.2.4) on the results is small. In addition, both models simulate a band of more convective precipitation over the ocean (see again Fig. 3), partly associated with the cold front of the cyclone, which will not be investigated in detail here, since no isotope data from this oceanic region are available.

All together, Figs. 2 and 3 show that the meteorological conditions during the winter storm in January 1986 are ad-

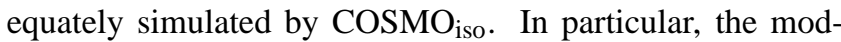
elled evolution of the temperature field, dominated by the passage of a large frontal system, and the track of the associated cyclone agree well with the ERA40 reanalysis data. With respect to precipitation, differences between the models are larger, also related to the huge impact of the horizontal resolution on the simulated spatial structures. When comparing isotope data from $\mathrm{COSMO}_{\text {iso }}$ with station observations, it should be kept in mind that there is some uncertainty related to the exact timing and intensity of the modelled precipitation at a specific location.

\subsubsection{Water isotopes}

For evaluating the new $\mathrm{COSMO}_{\text {iso }}$ model, first the isotope ratios in precipitation from the reference simulation 

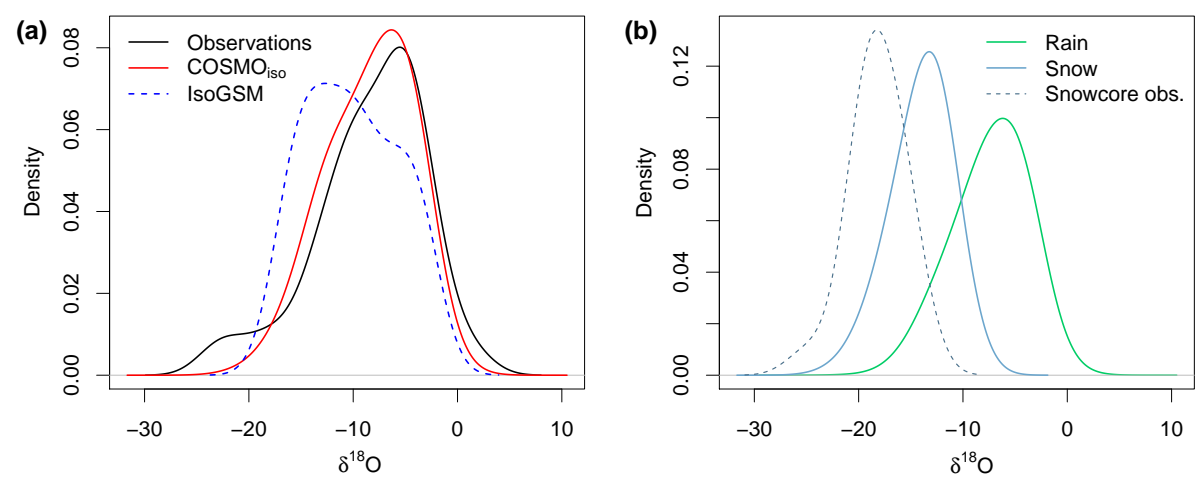

Fig. 4. (a) Probability density functions of $\delta^{18} \mathrm{O}$ (in $\%$ ) in three-hourly accumulated precipitation from observations by GL90 (black line) and the $\mathrm{COSMO}_{\text {iso }}$ reference simulation (red line). At a few stations where only six-hourly observations are available, these data are used. The blue dashed line shows the PDF of six-hourly data from an IsoGSM simulation. Model data from all land grid points between $28^{\circ} \mathrm{N}$ and $45^{\circ} \mathrm{N}$ latitude (for $\mathrm{COSMO}_{\text {iso }}$ and IsoGSM) as well as $105^{\circ} \mathrm{W}$ and $60^{\circ} \mathrm{W}$ longitude (for IsoGSM) are taken into account. Note that no weighting with precipitation intensity is performed. The PDFs have been fitted with a non-parametric method using Gaussian kernels. (b) PDFs of $\delta^{18} \mathrm{O}$ in three-hourly rain (green line) and snow (blue line) from COSMO iso. The blue dashed line shows the PDF of snowcore data from GL90.

are compared to observations by GL90 using statistical means. Probability density functions (PDFs) of $\delta^{18} \mathrm{O}$ in precipitation are fitted from both model data (for the analysis period 06:00 UTC 18 January to 06:00 UTC 21 January, cf. Sect. 2.3) and measurements using a non-parametric method with Gaussian kernels. Isotope data are not weighted with precipitation intensity, and all three- and six-hourly observations (137 in total) are considered in the same way. From the model, three-hourly data from land regions between $28^{\circ} \mathrm{N}$ and $45^{\circ} \mathrm{N}$ are used if the precipitation amount exceeds $0.3 \mathrm{~mm}$. This is roughly the region covered by observations (see again Fig. 1), taking into account that there is little to no precipitation in the western part of the model domain. The PDFs of $\delta^{18} \mathrm{O}$ in total precipitation are shown in Fig. 4a. There is a very good agreement between the $\mathrm{COSMO}_{\text {iso }}$ results and the observations. Both PDFs have a maximum close to $-6 \%$. The medians of the $\delta^{18} \mathrm{O}$ distributions from measurement and model data are $-7.4 \%$ o and $-7.9 \%$, respectively, and their interquartile ranges are $6.4 \%$ and $6.5 \%$. Only for very low and very high $\delta^{18} \mathrm{O}$ values, there are some differences between the PDFs. These deviations at the tails of the distributions, which are governed by isotope ratios in snow and very weak rain, might be related to insufficient observational sampling. The PDF from $\mathrm{COSMO}_{\text {iso }}$ is almost identical if six-hourly instead of three-hourly data are used, indicating that differences in the sampling time hardly influence the results. For comparison, Fig. 4a also shows a PDF of $\delta^{18} \mathrm{O}$ in precipitation from IsoGSM, the global model that is used for initialising the isotope ratios in water vapour (see Sect. 2.2.5). The PDF is fitted based on six-hourly output of precipitation rates, using land data from the same latitude range as for $\mathrm{COSMO}_{\text {iso }}$ and between $105^{\circ} \mathrm{W}$ and $60^{\circ} \mathrm{W}$ longitude. As can be seen from the figure, $\delta^{18} \mathrm{O}$ values from IsoGSM are in the same range as the observations, but the distribution is shifted to lower isotope ratios. The median of the IsoGSM data is $-10.4 \%$, and the interquartile range is $7.7 \%$. In Fig. 4b, PDFs of $\delta^{18} \mathrm{O}$ in rain and snow from $\mathrm{COSMO}_{\text {iso }}$ are displayed separately. There is a clear separation between higher values for rain, which constitutes the major part of the precipitation, and lower isotope ratios in snow. Unfortunately, no information on the phase of the precipitation is available from the station observations. Therefore, a PDF is only shown for the snowcore data gathered by GL90 in a relatively small area in West Virginia (21 separate measurements). These data are more depleted than the simulated $\delta^{18} \mathrm{O}$ values in snow. Nevertheless, this difference may well be due to the spatially very limited observational coverage.

These results show that $\mathrm{COSMO}_{\text {iso }}$ very accurately reproduces the statistical distribution of $\delta^{18} \mathrm{O}$ in precipitation during the winter storm in January 1986. Compared to a global model with lower spatial resolution, the more detailed representation of the synoptic processes leads to an improvement of these $\delta^{18} \mathrm{O}$ statistics. In the following, the spatial and temporal patterns of the water isotopes are compared to the station data. Figure 5 shows $\delta^{18} \mathrm{O}$ in six-hourly precipitation from observations by GL90 and the COSMO iso $_{\text {ref- }}$ erence simulation for the three dates previously displayed in Fig. 3. Model data are only shown where the six-hourly precipitation exceeds $0.6 \mathrm{~mm}$. Grey contours indicate the SLP

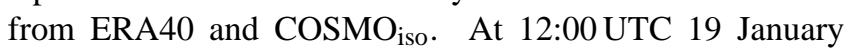
(Fig. 5a, d), $\delta^{18} \mathrm{O}$ ratios from both observations and model simulation are relatively high, in particular in a band reaching from the south-westerly edge of the precipitation region to the north-east. Lower values were observed at the westernmost station, in agreement with the model. At the two stations south of Lake Ontario, very high isotope ratios were measured. $\mathrm{COSMO}_{\text {iso }}$ does not simulate any precipitation at 

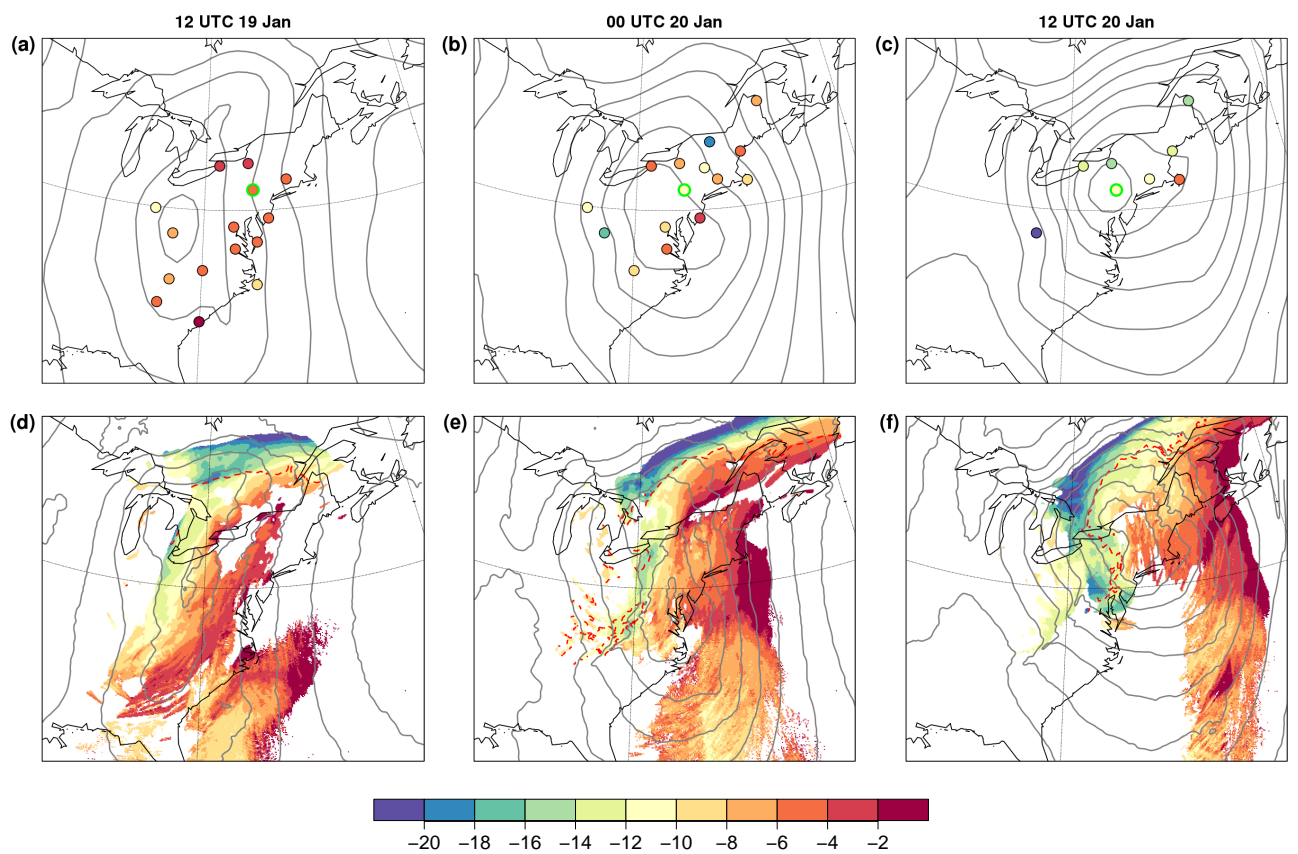

Fig. 5. $\delta^{18} \mathrm{O}$ in six-hourly accumulated precipitation (colours, in \%o) at (a, d) 12:00 UTC 19 January, (b, e) 00:00 UTC 20 January and (c, f) 12:00 UTC 20 January. As above, data are shown for periods three hours before to three hours after the respective dates. Panels

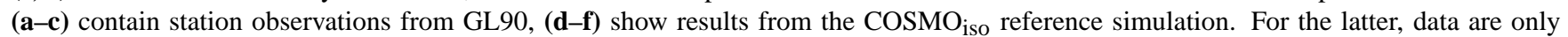
shown where the simulated six-hourly accumulated precipitation is larger than $0.6 \mathrm{~mm}$. Grey contours show the sea level pressure (contour interval $4 \mathrm{hPa}$ ) from ERA40 reanalyses $(\mathbf{a}-\mathbf{c})$ and $\mathrm{COSMO}_{\text {iso }}(\mathbf{d}-\mathbf{f})$. The station AVP is marked with a green outer circle in panels $(\mathbf{a}-\mathbf{c})$. The red dashed lines in (d-f) indicate the transition between rain and snow at the surface.

the locations of these stations, but does simulate high $\delta^{18} \mathrm{O}$ at the western shore of the lake. The agreement between model and observations is worse at the south-easterly coastal stations, where modelled precipitation rates are very heterogeneous. The lowest $\delta^{18} \mathrm{O}$ ratios are simulated in the very north, where solid precipitation reaches the ground, as indicated by the red dashed line marking the transition between rain and snow. The overall consistency between $\mathrm{COSMO}_{\text {iso }}$ and the isotope observations is worse at 00:00 UTC 20 January (Fig. 5b, e), in particular at the stations close to the Canadian border, where measured values are quite variable and do not resemble the spatial gradient simulated by the model. At the more southern stations, there is again a better agreement, with higher values at the coast and lower values further inland. $\mathrm{COSMO}_{\text {iso }}$ does not simulate precipitation as far west as it was observed (in contrast to the ECMWF model, see again Fig. 3), but nevertheless the low isotope ratios at the western edge of the precipitation region are similar to the measurements at the western stations. Finally, at 12:00 UTC 20 January both model and observations show rather low $\delta^{18} \mathrm{O}$ in precipitation over most of the continent (Fig. 5c, f). The agreement is again worst at the northeastern stations, but very good further south. As $12 \mathrm{~h}$ earlier, very low values were observed at the station in the west, which lies in the same area as the snowcores (see again GL90) that corroborate the low $\delta^{18} \mathrm{O}$ ratios in this region. $\mathrm{COSMO}_{\text {iso }}$ does not simulate precipitation there, but also an area of very depleted snow at the southwestern edge of the main precipitation band.

In summary, Fig. 5 shows that the large scale spatial patterns of $\delta^{18} \mathrm{O}$ in precipitation from the COSMO $\mathrm{Cis}_{\text {simulation }}$ are in good agreement with observations by GL90. In particular, there is a spatial gradient with high $\delta^{18} \mathrm{O}$ values at the eastern flank of the main precipitation band and lower values further west. The lowest isotope ratios are modelled and observed in the cold air, where snow reaches the surface. Furthermore, the temporal evolution observed at most of the stations, with high isotope ratios when precipitation starts and more depleted values later in time, is properly reproduced by the model. However, there are also deviations between $\mathrm{COSMO}_{\text {iso }}$ results and isotope observations, mostly on regional and local scales. This can be shown more explicitely by comparing time series at specific stations. As an example, the temporal evolution of precipitation and its isotopic composition at the station Avoca, Pennsylvania (AVP; green outer circle in Fig. 5a-c) is displayed in Fig. 6. During the 19th of January, there was little rainfall at this station ${ }^{3}$. The main precipitation band passed AVP shortly after 00:00 UTC

\footnotetext{
${ }^{3}$ Note that there are slight mismatches on this day between the timing of the isotope observations and the measured precipitation, which have been obtained from different sources.
} 

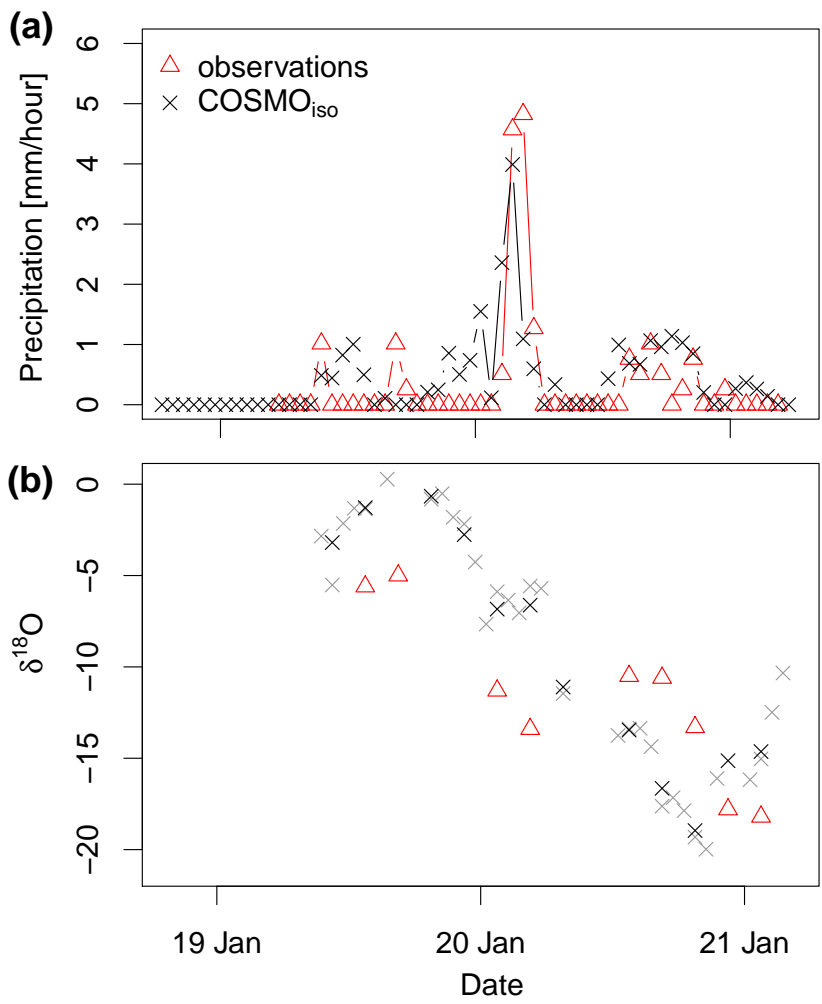

Fig. 6. Time series of hourly precipitation (a) and $\delta^{18} \mathrm{O}$ in precipitation, given in \%o (b) at station AVP (green outer circle in Fig. 5a-c). Precipitation amounts have been obtained from the National Climatic Data Center at NOAA. Grey crosses in (b) indicate hourly values, black crosses show three-hourly intensity-weighted averages, corresponding to the observation intervals. $\mathrm{COSMO}_{\text {iso }} \delta^{18} \mathrm{O}$ data are only shown if the simulated precipitation is larger than $0.1 \mathrm{~mm}$ per hour.

20 January, followed by some hours without rain and several smaller showers on late 20 and early 21 . This precipitation time series is properly reproduced by $\mathrm{COSMO}_{\text {iso. }}$. Only before the passage of the main front, some rain is simulated that was not observed at the station. The isotope ratios in precipitation from both model and measurements are relatively high during the 19th and decrease on the 20th of January (Fig. 6b). The model overestimates the $\delta^{18} \mathrm{O}$ in the beginning and during the precipitation maximum and does not capture the slight increase that was observed at the onset of the showers on the 20th. One reason for this mismatch may be the strong spatial variability of the isotope ratio in precipitation (see again Fig. 5). Due to this, even small errors in the simulation of the spatial structure of the precipitation field may have a large impact on the $\delta^{18} \mathrm{O}$ time series at a specific location. Furthermore, GL90 showed that several mesoscale cloud bands influenced the showers at station AVP during the 20th of January. Such mesoscale structures are more difficult to simulate than the large scale synoptic evolution.

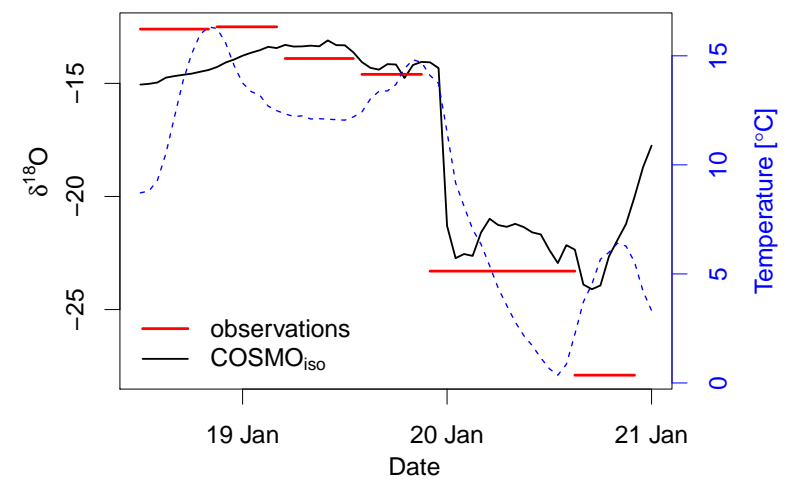

Fig. 7. Time series of $\delta^{18} \mathrm{O}$ in water vapour (in \%o) at station RDU (white cross in Fig. 1) from observations and the $\mathrm{COSMO}_{\text {iso }}$ reference simulation. Note the differing lengths of the periods over which the vapour has been sampled. The blue dashed line shows the simulated temperature. All $\mathrm{COSMO}_{\text {iso }}$ data are taken from the lowest model level, approximately 10 metres above ground.

In contrast to $\delta^{18} \mathrm{O}$ of precipitation, GL90 sampled the isotopic composition of water vapour only at one location, the station RDU in North Carolina (white cross in Fig. 1). Figure 7 shows the observed and modelled time series at this station. Isotope ratios were on the order of $-15 \%$ during the 19th and suddenly dropped to below $-23 \%$ around 00:00 UTC 20 January. COSMO ${ }_{\text {iso }}$ captures these values and also the timing of the drop very well. The modelled temperature, which is also shown in Fig. 7, indicates that the decrease in the isotope ratio is related to the passage of the front. Only during the late 20th, there is a discrepancy between the observed and simulated time series, which might again be due to problems with modelling the exact location of the strong spatial gradients of $\delta^{18} \mathrm{O}$ in water vapour, discussed further in Sect. 3.2.

In order to further compare the $\mathrm{COSMO}_{\text {iso }}$ results to those from the global IsoGSM simulation, Fig. 8 shows six-hourly precipitation rates and corresponding $\delta^{18} \mathrm{O}$ values from the global model. Since the large scale circulation of IsoGSM is nudged to reanalysis data (see again Yoshimura et al., 2008), the model, in spite of its coarse spatial resolution, reproduces the large scale features of the frontal precipitation rather well (cf. Fig. 3). The same is true for the spatial distribution of the isotope ratios (cf. Fig. 5), for which the model, similar to $\mathrm{COSMO}_{\text {iso, }}$, simulates a west-to-east gradient with more depleted values in the cold air to the west of the front. This is related to a gradual decrease of $\delta^{18} \mathrm{O}$ in time at most locations in the eastern US, and leads to a reasonable representation of the temporal evolution of the isotopic composition of precipitation and water vapour at the stations discussed above (not shown). Nevertheless, a comparison of Figs. 8 and 5 also illustrates the major gain obtained from the high-resolution $\mathrm{COSMO}_{\text {iso }}$ simulation, in which synoptic- and regional-scale spatial structures are represented in a more realistic way than in the coarse IsoGSM data. 

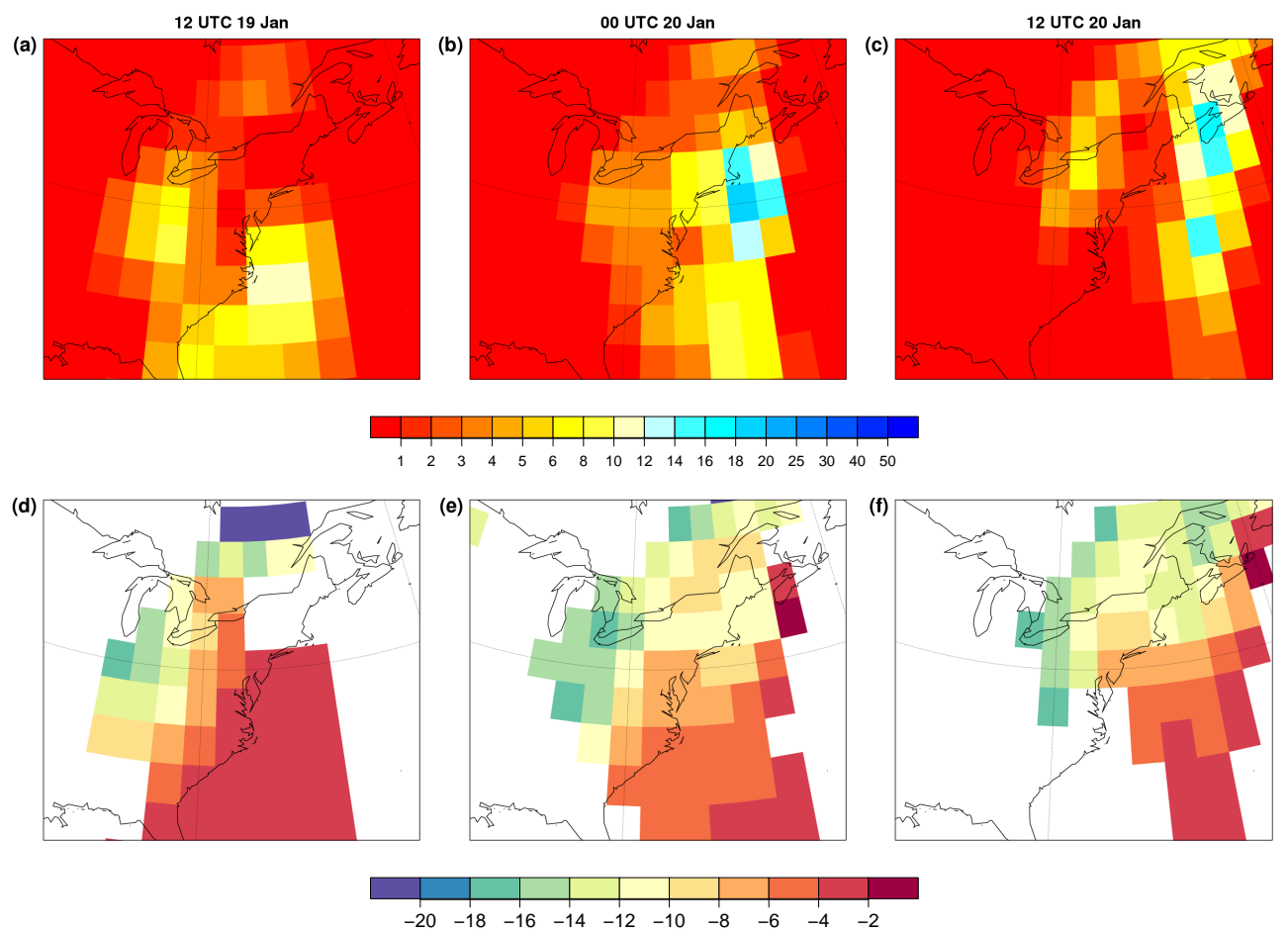

Fig. 8. (a-c) Precipitation rate (in mm per 6 hours) and (d-f) the corresponding $\delta^{18} \mathrm{O}$ from the IsoGSM simulation at (a, d) $12: 00 \mathrm{UTC} 19$ January, (b, e) 00:00 UTC 20 January and (c, f) 12:00 UTC 20 January. Isotope data are only shown where the simulated precipitation rate is larger than $0.6 \mathrm{~mm}$ per 6 hours.

The results from this section show that for the winter storm event investigated here, $\mathrm{COSMO}_{\text {iso }}$ is able to simulate the synoptic-scale variability of $\delta^{18} \mathrm{O}$ in atmospheric waters in good agreement with observations. Based on this, the model can be applied for investigating the physical processes causing such variability. This will be the focus of the next section. Nevertheless, it has to be kept in mind that the model cannot exactly reproduce mesoscale structures and local variations. Therefore, care has to be taken when interpreting time series of the isotopic composition at single locations.

\subsection{Processes determining isotope ratios in frontal pre- cipitation}

Most of the continental precipitation during the winter storm in January 1986 fell in the region of the evolving cyclonic system crossing the eastern US between 19 and 21 January. The most prominent spatial $\delta^{18} \mathrm{O}$ pattern in this precipitation is the across-front gradient, with high isotope ratios at its eastern (warm) and low values at its western (cold) side (see again Fig. 5). Direct evidence for similar spatial patterns from other storm events are rare, owing to the lack of spatially distributed isotope observations and model studies on synoptic scales (cf. Sect. 1). The spatial east-west gradient is connected to a temporal evolution with high $\delta^{18} \mathrm{O}$ values in the beginning and a decrease later on at stations where the front passes by (cf. Fig. 6). Such a decrease was ob- served in previous studies on mid-latitude weather systems, e.g., by Rindsberger et al. (1990), Celle-Jeanton et al. (2004) and Coplen et al. (2008) ${ }^{4}$. The spatial gradient and corresponding time evolution thus appear to be rather typical for mid-latitude frontal systems. Understanding the processes driving this isotopic gradient is the focus of the present section.

One advantage of a model-based investigation of synopticscale isotope variability, compared to discrete observations at specific stations, is the complete spatial and temporal coverage, which can provide additional insights into the relationship between meteorological and isotopic fields. Figure 9 shows the spatial distribution of $\delta^{18} \mathrm{O}$ in water vapour on $850 \mathrm{hPa}$ at five dates within the analysis period. There is a relatively close correspondence between these fields and the temperature on $850 \mathrm{hPa}$ plotted in Fig. 2. Isotope ratios are rather high in the warm, pre-frontal air and lower in the cold air mass that has been transported into the domain from the north-west. This distribution points towards a large-scale control of the different air masses on the $\delta^{18} \mathrm{O}$ gradient in precipitation along the front. In the pre-frontal air, clouds and precipitation form from (and equilibrate with) enriched water vapour, and thus $\delta^{18} \mathrm{O}$ in precipitation also is relatively high.

\footnotetext{
${ }^{4}$ Note that in many of these cases there was again an increase of $\delta^{18} \mathrm{O}$ at the very end of the precipitation, which did not occur during the winter storm event investigated here.
} 

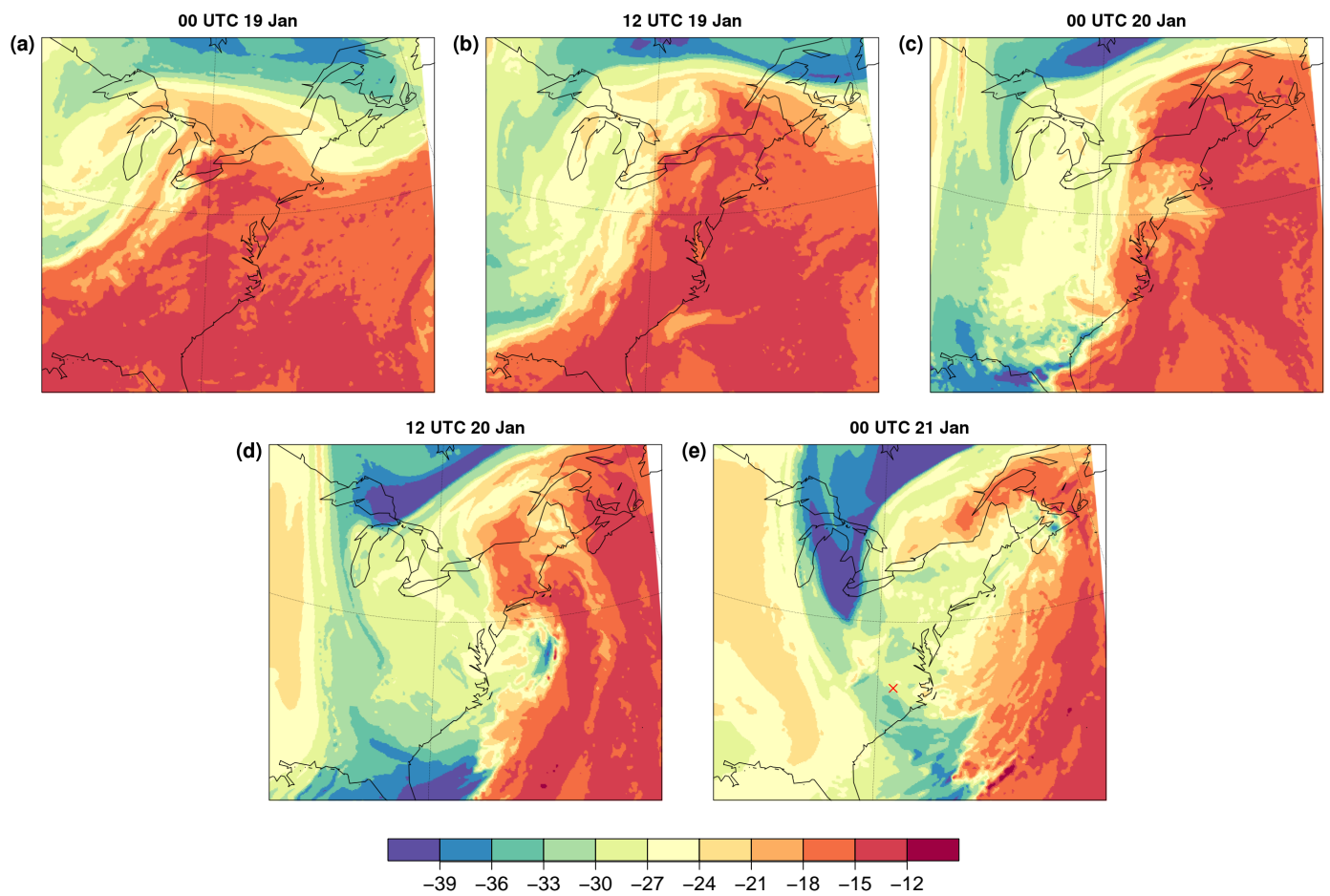

Fig. 9. $\delta^{18} \mathrm{O}$ in water vapour (in $\%$ ) on $850 \mathrm{hPa}$ at (a) 00:00 UTC 19 January, (b) 12:00 UTC 19 January, (c) 00:00 UTC 20 January, (d) 12:00 UTC 20 January and (e) 00:00 UTC 21 January from the COSMO $_{\text {iso }}$ reference simulation. The red cross in panel (e) indicates the location of the station RDU.

Behind the front, more depleted water vapour leads to lower $\delta^{18} \mathrm{O}$ in precipitation. This process is strongly related to the classical temperature effect (Dansgaard, 1964), which provides the basis for water isotope paleo-thermometry. Water vapour in colder air further poleward has, on average, been exposed to more condensation and removal of heavy isotopes than warmer (and in the present case also more oceanic) air in the south, leading to a climatological decrease of $\delta^{18} \mathrm{O}$ in vapour (and thereby precipitation) with temperature (see also Liu et al., 2010). This effect is mainly imprinted on the $\mathrm{COSMO}_{\text {iso }}$ vapour field by the initial and boundary conditions. However, the large scale relationship between $\delta^{18} \mathrm{O}$ in vapour and frontal precipitation observed here is not only due to a climatological pre-conditioning of the vapour, but there is also a contribution by the weather system itself, which induces gradual rainout and isotopic depletion of the vapour along the front.

In addition to the climatological decline of $\delta^{18} \mathrm{O}$ in water vapour with decreasing temperature in the horizontal, there is also a decrease with altitude, owing to the progressive removal of heavy isotopes when air rises and cools. GL90, using cloud top temperature observations from satellites, argued that because of this vertical gradient the altitude of precipitation formation influenced the isotopic composition of surface precipitation during the 1986 storm. In order to investigate if this effect contributes systematically to the horizontal gradient in $\delta^{18} \mathrm{O}$ in precipitation perpendicular to the front, a vertical cross section along the dashed green line in Fig. 3d at 12:00 UTC 19 January is shown in Fig. 10. In addition to the specific moisture content of non-precipitating and precipitating hydrometeors, the figure shows the isotopic composition of water vapour as well as rain and snow. The simulated surface cold front at this instant is located in a distance of approximately $600 \mathrm{~km}$ from the westernmost point of the cross section, as indicated by the isentropes included in Fig. 10a. From Fig. 10b, the strong horizontal contrast between the enriched water vapour on the warm side of and the more depleted vapour behind the front becomes obvious. This horizontal gradient is dominant up to a height of about $5-6 \mathrm{~km}$. Moreover, there is a decrease of $\delta^{18} \mathrm{O}$ with altitude, as mentioned above. The isotopic composition of the water vapour is reflected in the $\delta^{18} \mathrm{O}$ of the precipitate, as indicated by Fig. 10d. Nevertheless, no systematic changes in cloud height or height of precipitation formation with distance from the front is obvious from Fig. 10a and c. In particular, it is not the case that precipitation to the west of the front has been formed in deeper clouds than on its eastern side. Only at the western end of the cross section, there are some boundary layer clouds with more enriched isotopic composition than in the frontal region. These boundary layer clouds do not lead to any substantial surface precipitation (see again Fig. 3), but one can speculate that similarly shallow clouds contributed to the increase in $\delta^{18} \mathrm{O}$ late during the events observed in other studies (see again Rindsberger et al., 1990; 
(a)
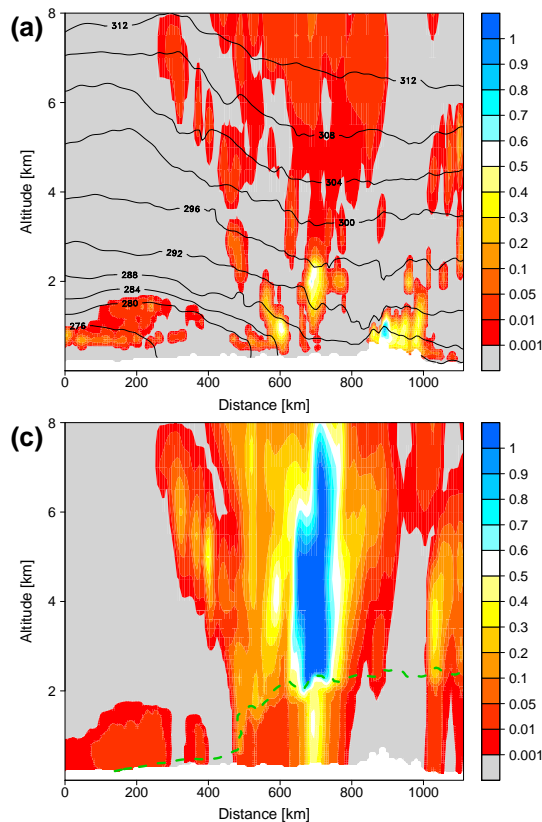

(e)

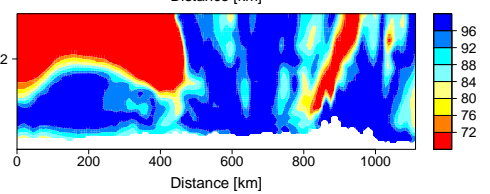

(b)

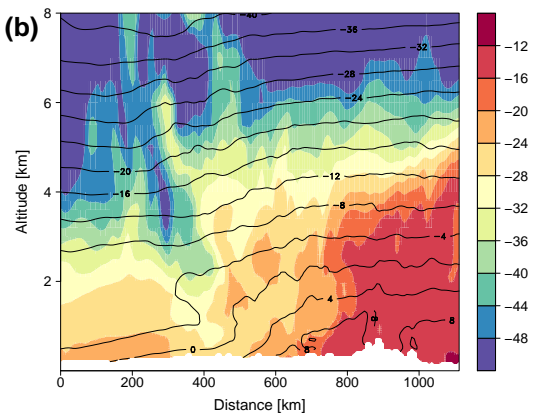

(d)

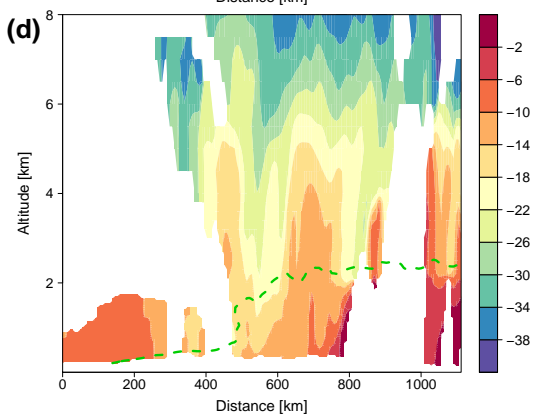

(f)

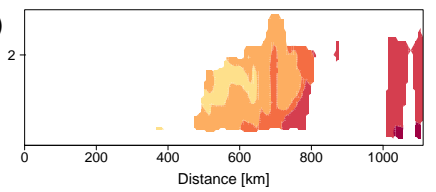

Fig. 10. Vertical cross sections from the $\operatorname{COSMO}_{\text {iso }}$ reference simulation at 12:00 UTC 19 January of (a) the sum of cloud water and ice content (in $\mathrm{g} \mathrm{kg}^{-1}$ ), (b) $\delta^{18} \mathrm{O}$ of water vapour (in \%o), (c) the sum of rain and snow water content (in $\mathrm{g} \mathrm{kg}^{-1}$ ), (d) $\delta^{18} \mathrm{O}$ of rain and snow (in $\% o$ ), (e) relative humidity and (f) $\delta^{18} \mathrm{O}$ of rain in isotopic equilibrium with water vapour along the green dashed line shown in Fig. $3 \mathrm{~d}$. The horizontal axis gives the distance in $\mathrm{km}$ to the westernmost point of the cross section. The contours in (a) and (b) show potential temperature (in $\mathrm{K}$ ) and temperature (in ${ }^{\circ} \mathrm{C}$ ), respectively. The green dashed lines in (c) and (d) indicate the $0{ }^{\circ} \mathrm{C}$ isoline. In (e) and (f), only the lowest part of the section is shown. The colour scale of panel (d) is also valid for (f).

Celle-Jeanton et al., 2004; Coplen et al., 2008). For the front investigated here, there is no obvious systematic effect of cloud height on the $\delta^{18} \mathrm{O}$ gradient, in agreement with other recent modelling studies (Yoshimura et al., 2010; Risi et al., 2010a).

In addition to the large scale control of air mass isotopic composition on the frontal $\delta^{18} \mathrm{O}$, microphysical processes may be important, in particular the interaction of rain drops and water vapour beneath the cloud base (see again GL90). This is also obvious from Fig. 10b and d. Close to the eastern end of the cross section, relatively depleted snow falls into layers with higher $\delta^{18} \mathrm{O}$ in vapour. As soon as the snow flakes pass the $0{ }^{\circ} \mathrm{C}$ level, they start melting, and the resulting raindrops interact with the surrounding vapour. By equilibration and isotopic fractionation during evaporation, the isotopic composition of the rain changes relatively fast, particularly where the specific rain content is low, leading to a pronounced vertical gradient of $\delta^{18} \mathrm{O}$ in the precipitation. In regions where the relative humidity is close to $100 \%$ (see Fig. 10e), equilibration drives the isotopic composition of the rain towards the equilibrium composition with respect to the surrounding vapour, which is displayed in Fig. 10f. In particular on the eastern flanks of the precipitation regions, lower relative humidity causes evaporation of rain drops, and the associated isotopic fractionation leads to an enrichment of the rain compared to the equilibrium composition (cf. Figs. 10d and f). Further west, near and behind the front, there is less change of the rain composition due to these postcondensational process, because the melting level is at lower altitudes, rain rates are larger (at least at some locations) and the boundary layer moisture is more depleted.

For investigating the effect of rain-vapour interactions on the frontal gradient more explicitely, a sensitivity experiment is performed with isotopic fractionation during these interactions switched off (see Sect. 2.3). Figure 11 shows the isotopic composition of water vapour as well as rain and snow along the cross section from this experiment. The differences in the isotopic composition of the rain are strongest in the easternmost part of the cross section and near the horizontal distance of $800 \mathrm{~km}$, where the rain in the sensitivity experiment is more depleted than in the reference simulation, leading to a reduction of the $\delta^{18} \mathrm{O}$ gradient at the surface in the experiment (cf. Fig. 10d and 11b). This is in agreement with the results of GL90 and corroborates the importance of 

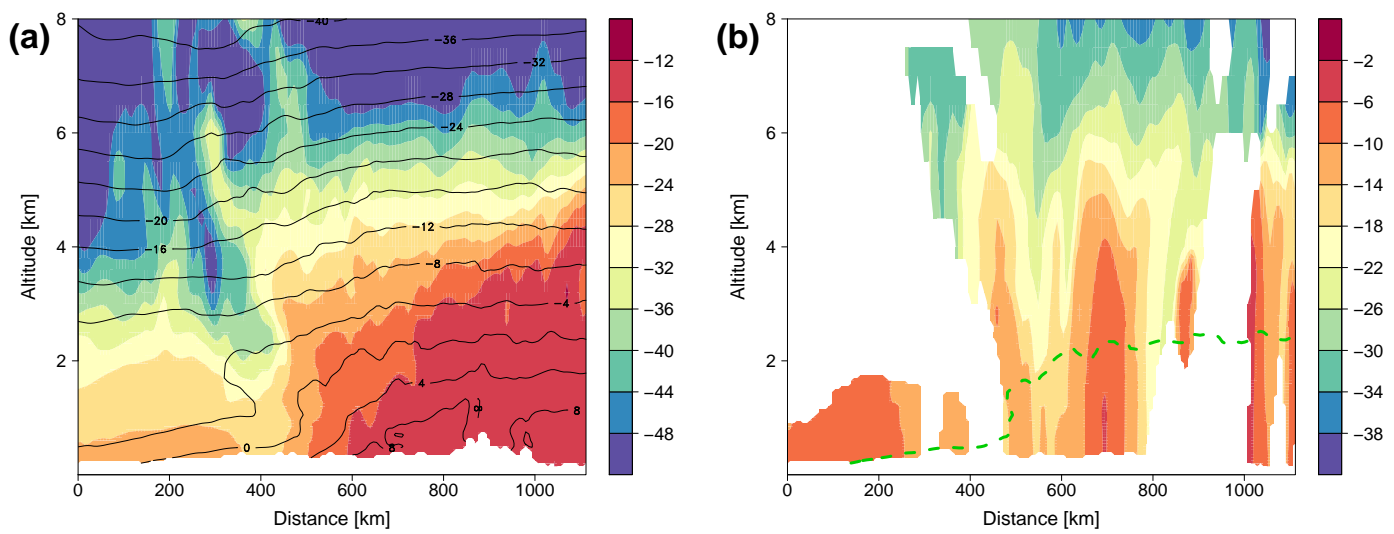

Fig. 11. Vertical cross sections from the $\mathrm{COSMO}_{\text {iso }}$ sensitivity experiment in which isotopic fractionation during the interaction of rain drops and the surrounding water vapour is switched off, showing $\delta^{18} \mathrm{O}$ (in \%o) in (a) water vapour and (b) rain and snow at 12:00 UTC 19 January along the green dashed line given in Fig. 3d. The contours in (a) show the temperature (in $\left.{ }^{\circ} \mathrm{C}\right)$, the green dashed line in (b) indicates the $0{ }^{\circ} \mathrm{C}$ isoline.

the microphysical interactions between raindrops and vapour for this spatial gradient, as outlined above. With respect to the isotopic composition of the vapour (Fig. 10b and 11a), the strongest differences between the two simulations can be found in the region of the front, where $\delta^{18} \mathrm{O}$ values in the sensitivity study are distinctly higher. The reason for this is that, owing to the more depleted rain, less heavy isotopes are removed from the atmosphere by precipitation (see also Field et al., 2010). The area with substantial differences in the vapour composition reaches altitudes well above the melting level, indicating the ventilation of air from below (which has been in contact with liquid precipitation) to these heights. In the region of strongest rainfall around $700 \mathrm{~km}$, this induces a feedback on the isotopic composition of the precipitation. Isotope ratios of the snow forming from the enriched vapour above the melting layer are also higher than in the reference simulation. At some locations this enrichment overcompensates the effect of raindrop interactions further below and leads to slightly higher $\delta^{18} \mathrm{O}$ values at the surface.

In Fig. 12, the isotopic composition of water vapour on $850 \mathrm{hPa}$ and surface precipitation at 12:00 UTC 19 January from the sensitivity experiment are shown, as well as differences in these fields compared to the reference simulation. As indicated by Fig. 12a and c, isotopic fractionation during raindrop-vapour interactions typically reduces the $\delta^{18} \mathrm{O}$ ratio of the vapour, as described above. However, this reduction is mainly restricted to the area where precipitation occurs, indicating that the microphysical processes are important for the regional-scale $\delta^{18} \mathrm{O}$ pattern along the front, but do not strongly affect the large scale differences between cold and warm air isotopic composition (away from the front, there is hardly any difference between the two experiments). Figure $12 \mathrm{~b}$ and $\mathrm{d}$ demonstrate once again that microphysical interactions between raindrops and the surrounding vapour contribute to the east-west gradient of $\delta^{18} \mathrm{O}$ in precipitation perpendicular to the front, mainly by enrich- ing the rain in the eastern part of the frontal band. Only in the north of the model domain and at the western side of the front, there are regions where $\delta^{18} \mathrm{O}$ in the sensitivity study is higher than in the reference run. These are mainly areas where precipitation falls as snow, which is not affected by post-condensational isotope effects. The higher values there are caused by the less depleted water vapour. This feedback of the post-condensational effects on vapour and snow isotopic composition is particularly large in the area of strongly depleted snow in the south-western part of the precipitation band at 12:00 UTC 20 January (not shown; cf. Fig. 5). This is again in agreement with the results of GL90, who also found that recycled moisture, which had been in contact with rain beforehand, contributed to the source vapour of the snow in the cold air behind the front.

\subsection{Temperature effect}

As outlined in the previous section, the fact that the isotopic composition of precipitation on the warm side of the front is more enriched than on its cold side, which is of course immanent in the frontal gradient analysed in Sect. 3.2, is a realisation of the classical temperature effect. This effect is the basis for employing water isotope data, e.g., from ice cores, as temperature proxies on long, climatological time scales. Here, the results of the $\mathrm{COSMO}_{\text {iso }}$ simulations are used for investigating to which extent the effect also explains shortterm variations in the isotopic composition of precipitation during the 1986 winter storm. Therefore, correlation coefficients $r$ are calculated between hourly time series of the 2$\mathrm{m}$ temperature and $\delta^{18} \mathrm{O}$ of precipitation from the reference simulation at each grid point with 15 or more data points (i.e., 15 or more hours with precipitation larger than $0.1 \mathrm{~mm}$ in the analysis period). These correlations are shown in Fig. 13a. The values of $r$ are positive over most of the southern part of the precipitation region, with maxima near the US east coast 

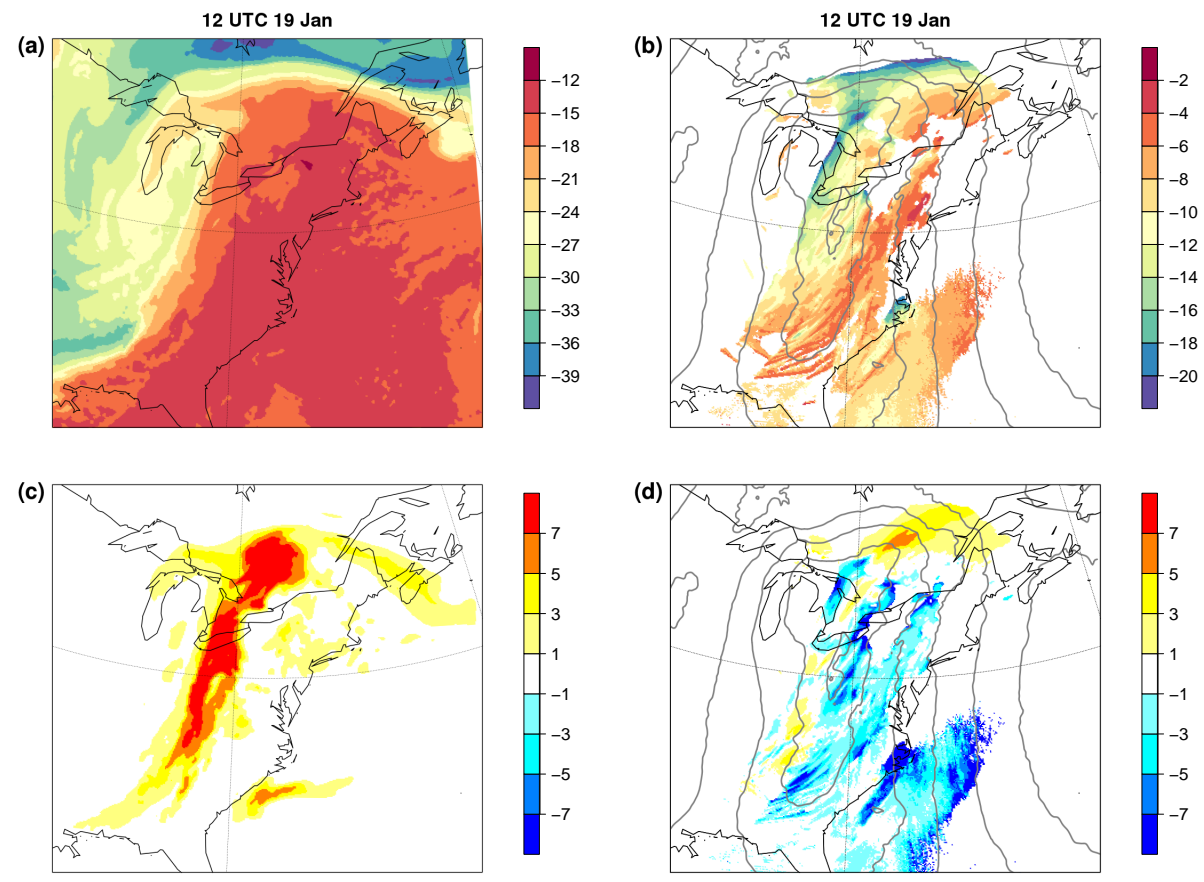

Fig. 12. $\delta^{18} \mathrm{O}$ (in \%o) in (a) water vapour on $850 \mathrm{hPa}$ and (b) six-hourly accumulated precipitation at 12:00 UTC 19 January from the sensitivity experiment in which isotopic fractionation during the interaction of rain drops and the surrounding water vapour is switched off. Difference plots of $\delta^{18} \mathrm{O}$ (in \%o) in six-hourly precipitation and in water vapour on $850 \mathrm{hPa}$ between sensitivity experiment and reference simulation are shown in (c) and (d), respectively.

and in the Great Lakes area. Further north, the correlation pattern is more patchy, and there are considerably negative values of $r$ at some locations, e.g., in the very north-west and over New England. The latter is consistent with the observations by GL90, who also found a negative temperature- $\delta^{18} \mathrm{O}$ correlation at a station in Portland, Maine and positive relationships at most of the other sites. The negative values of $r$ over New England (and parts of the North Atlantic) are due to the fact that in the simulation most rainfall in this region occurs during the warm air advection before the passage of the front. The heavy isotopes in this warm air become more and more depleted when the rain accumulates, which relates to the so-called amount effect (see again GL90 and also Risi et al., 2008). All together, this shows that the temperature effect explains a substantial part of the short-term $\delta^{18} \mathrm{O}$ variability in several regions, even for this single event. However, on local scales other mechanisms can be of greater importance. This may be different if longer periods, comprising several mid-latitude precipitation events, are analysed.

The discussion in Sect. 3.2 has shown that, in addition to the large scale air mass advection, microphysical interactions between rain and water vapour are important drivers of $\delta^{18} \mathrm{O}$ variations in the frontal precipitation. The magnitude of such post-condensational effects is to some extent determined by the height of the melting level. If this is low, precipitation falls mostly as snow, which does not interact with the surrounding vapour. On the other hand, if the melt- ing level is far above the ground, there is more time for the raindrops to equilibrate with the vapour. Therefore, the melting level height, which is of course correlated with the nearsurface temperature, is supposed to be a more physical determinant of the isotope ratio than the temperature alone. Figure $13 \mathrm{~b}$ shows the correlation coefficients between time series of melting level height (i.e., the height of the $0^{\circ} \mathrm{C}$ isoline above ground) and $\delta^{18} \mathrm{O}$ in hourly precipitation. No values are shown at locations where the temperature on the lowest model level is always below $0{ }^{\circ} \mathrm{C}$. Compared to Fig. 13a, the correlation is larger over most of the continental regions, except for the southwest and parts of Canada. In Fig. 13c, the same correlation is shown for the sensitivity experiment in which isotopic fractionation during raindrop-vapour interactions is switched off. The values of $r$ are greatly reduced and much more patchy compared to the reference simulation. The temperature- $\delta^{18} \mathrm{O}$ correlations from the sensitivity study are similarly reduced (not shown). This demonstrates the importance of post-condensational processes for the temperature effect during the 1986 storm event. Similar results were obtained by Field et al. (2010) for the mid-latitude temperature effect on monthly time scales. 

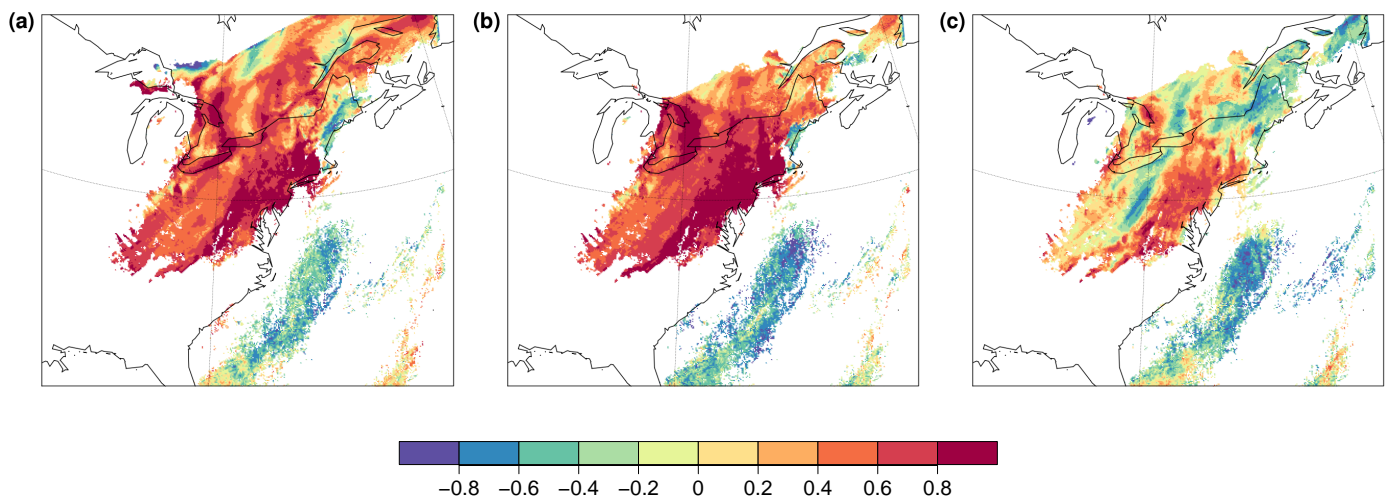

Fig. 13. (a) Correlation coefficients between time series of 2-meter temperature and $\delta^{18} \mathrm{O}$ in hourly precipitation from the $\mathrm{COSMO}_{\text {iso }}$ reference simulation. Values are only shown at grid points with 15 or more hours of precipitation (meaning that the simulated precipitation is larger than $0.1 \mathrm{~mm}$ per hour). (b) Correlation coefficients between time series of the height above ground of the $0^{\circ} \mathrm{C}$ isoline and $\delta^{18} \mathrm{O}$ in hourly precipitation. (c) As in (b), but for the sensitivity experiment in which isotopic fractionation during the interaction of rain drops and the surrounding water vapour is switched off. In (b) and (c), in addition to grid points with too little precipitation hours, also points are masked where the temperature on the lowest model level is always below $0{ }^{\circ} \mathrm{C}$.

\section{Conclusions}

In this study, a stable water isotope module has been implemented in the limited-area weather forecast and climate model COSMO. This module contains a detailed representation of isotope fractionation processes during phase transitions in the atmospheric water cycle. The new $\mathrm{COSMO}_{\text {iso }}$ model includes an advanced microphysical scheme, a convection parameterisation and non-hydrostatic dynamics that facilitate simulations from sub-kilometre to synoptic spatial scales. As a first test case, the model has been applied for simulating a winter storm over the eastern United States in January 1986. The modelled isotopic composition of precipitation has been compared to spatially distributed observations from a study by GL90. COSMO iso almost perfectly reproduces the statistical distribution of the $\delta^{18} \mathrm{O}$ ratios, and also the large scale spatial structure and temporal evolution are properly simulated. Deviations at single stations can partly be attributed to errors in the representation of mesoscale atmospheric structures in the model.

Based on the $\mathrm{COSMO}_{\text {iso }}$ results, the typical time evolution of enriched rainfall in the beginning of mid-latitude precipitation events and a progressive depletion in the course of the event has been linked to a spatial gradient of $\delta^{18} \mathrm{O}$ in surface precipitation. High isotope ratios are simulated on the warm side of the front that triggered the major part of the rainfall during the 1986 winter storm, and more depleted precipitation in the cold air on its back side. Two major processes have been identified that contribute to creating this spatial pattern. First, the advection of cold, depleted water vapour to the west and warm, more enriched vapour eastwards of the front, in concert with the progressive removal of heavy isotopes by precipitation in the frontal band, causes a large scale east-west gradient of $\delta^{18} \mathrm{O}$ of vapour and precipitation.
Second, this large scale pattern is modulated by microphysical effects, namely the isotope fractionation and equilibration during the interaction of rain drops and water vapour. As opposed to this, there is no evidence from the model results that differences in the altitude of precipitation formation contribute systematically to the frontal isotopic gradient. The important role of these two processes explains the temperature effect that is simulated by $\mathrm{COSMO}_{\text {iso }}$ for most of the continental precipitation. Since near-surface temperature is, on the one hand, a measure of large scale air mass properties and, on the other hand, related to post-condensational effects via the height of the melting level, it correlates with the isotopic composition of frontal precipitation. For the case investigated here, the height of the melting level itself is an equally good predictor of $\delta^{18} \mathrm{O}$ in precipitation. In future research, the generality of the results obtained from this case study should be investigated. It will be interesting to see in which way the isotopic patterns in frontal precipitation and the mechanisms behind them depend on the specific meteorological evolution of the cyclone or the region where it occurs.

With respect to the overall aim of using isotopes as tracers of weather-related processes, the present study does not provide definitive answers, but can be seen as a promising starting point. The interplay of large-scale and microphysical processes in causing $\delta^{18} \mathrm{O}$ variability makes the interpretation of these isotope signals relatively complex, and it is unlikely that they can be directly related to single physical mechanisms. Rather, a combined approach, using stable water isotope observations together with model simulations, is promising for obtaining deeper insights into physical processes like cloud microphysics and water transport. Using the additional constraints on the simulated water cycle provided by the isotopes, specific processes in the model may be evaluated. For instance, based on the important role of 
rain-vapour interaction and moisture recycling for the strong depletion of the post-frontal snow in the present case study (see Sect. 3.2), the isotopic composition of this snow may be applied as a measure for the correct representation of such recycling mechanisms in the model.

The new $\mathrm{COSMO}_{\text {iso }}$ limited-area isotope model is a flexible tool that may be used in a variety of applications in future research. It is well suited for supporting the interpretation of observations with high temporal resolution, which are becoming more and more available. More specifically, the model can also be used for testing parameterisations of isotope fractionation, e.g., with respect to ice formation. With the prognostic ice supersaturation of the $\mathrm{COSMO}_{\text {iso }}$ microphysics scheme, the effect of supersaturation on kinetic fractionation may be investigated more explicitely than using the parametric equations employed in most other isotope models. Furthermore, different realisations of the Craig-Gordon model can be compared with the help of deuterium excess data, ideally from near-surface water vapour (cf. Sect. 2.2.2). The model will have to be extended when isotope fluxes between the atmosphere and the land surface shall be investigated (see again Sect. 2.2.2). Also, with respect to convection and microphysics, more sophisticated parameterisations (e.g., a two-moment microphysics scheme) may be implemented in the future. Finally, the model can also be applied for climate simulations in order to investigate regional water isotope variability on monthly or longer time scales.

\section{Appendix A}

\section{Advection of isotope tracers}

As outlined in Sect. 2.2.1, a modified Bott scheme is applied for the advection of heavy isotopes, similar to the approach followed by Risi et al. (2010b) using the Van Leer scheme. Here, this is detailed for one spatial dimension; the extension to three dimensions is done with the time splitting method. The specific humidities $q$ are multiplied with the total air density $\rho$ before advection for obtaining moisture densities $\psi=q \cdot \rho$. Following Bott (1989), the moisture field after advection $\psi^{\prime}$ at grid point $i$ is given by

$\psi_{i}^{\prime}=\psi_{i}-\frac{\Delta t}{\Delta x}\left(F_{i+1 / 2}-F_{i-1 / 2}\right)$,

where $\Delta t$ and $\Delta x$ denote the time step and grid spacing, respectively, and $F_{i+1 / 2}$ is the moisture flux through the right boundary of the grid cell. For the standard light isotope ${ }^{1} \psi$, these fluxes are obtained from the classical Bott scheme, as described in detail by Bott (1989). This is done by approximating ${ }^{1} \psi$ in grid box $i$ with a polynomial:

${ }^{1} \psi_{i}(\hat{x})=\sum_{k=0}^{4} a_{k} \hat{x}^{k}$
Here, $\hat{x}=\left(x-x_{i}\right) / \Delta x$ is between $-1 / 2$ and $1 / 2$. The coefficients $a_{k}$ can be obtained from the value of ${ }^{1} \psi$ at the neighbouring grid points. The order of the polynomial, which is chosen to be 4 here, determines the accuracy of the scheme. The flux of the light isotope is given by

${ }^{1} F_{i+1 / 2}=\frac{\Delta x}{\Delta t} \cdot \mathcal{L}\left({ }^{1} f_{i+1 / 2}\right)$,

with

${ }^{1} f_{i+1 / 2}= \begin{cases}\int_{1 / 2-c_{i+1 / 2}}^{1 / 2} \psi_{i}(\hat{x}) d \hat{x} & , \quad c_{i+1 / 2} \geq 0 \\ \int_{-1 / 2}^{-1 / 2-c_{i+1 / 2} 1} \psi_{i+1}(\hat{x}) d \hat{x}, & c_{i+1 / 2}<0\end{cases}$

and $\mathcal{L}(.$.$) denoting a flux limiting operator that is neces-$ sary for the positive definiteness (for details, see again Bott, 1989). Moreover, $c_{i+1 / 2}=u_{i+1 / 2} \Delta t / \Delta x$ is the Courant number, with $u$ denoting the wind velocity. The integrals in Eq. (A4) can be evaluated analytically by plugging in the polynomial expansion from Eq. (A2).

For the heavy isotopes, instead of using Eqs. (A2) to (A4) directly, the fluxes are determined by interpolating the isotope ratio $R={ }^{\mathrm{h}} \psi /{ }^{1} \psi$ (rather than the moisture density):

$R_{i}(\hat{x})=\sum_{k=0}^{4} a_{R, k} \hat{x}^{k}$,

where the coefficients $a_{R, k}$ can be determined from the values of $R$ at the neighbouring grid points, as above for ${ }^{1} \psi$. Therewith, the heavy isotope fluxes are given by

${ }^{\mathrm{h}} F_{i+1 / 2}=\frac{\Delta x}{\Delta t} \cdot \mathcal{L}\left({ }^{1} f_{i+1 / 2}{ }^{R} f_{i+1 / 2}\right)$,

with

${ }^{R} f_{i+1 / 2}= \begin{cases}\frac{1}{c_{i+1 / 2}} \int_{1 / 2-c_{i+1 / 2}}^{1 / 2} R_{i}(\hat{x}) d \hat{x}, & c_{i+1 / 2}>0 \\ -\frac{1}{c_{i+1 / 2}} \int_{-1 / 2}^{-1 / 2-c_{i+1 / 2}} R_{i+1}(\hat{x}) d \hat{x} & c_{i+1 / 2}<0 .\end{cases}$

The flux limitation denoted by $\mathcal{L}(.$.$) is performed analo-$ gously to the standard scheme used for the light isotopes. In case of vanishing moisture content at neighbouring grid points (which occurs frequently for all hydrometeors), $R$ is ill-defined. In this case, the integrity of the scheme is maintained by reducing the order of the polynomial in (A7) to second or even zeroth order (corresponding to a simple upstream scheme) at the respective grid points. Finally, the change of heavy isotope content due to advection is obtained by combining Eqs. (A5) to (A7) with Eq. (A1). This modified advection scheme, which can basically be applied for arbitrary tracers, has a high accuracy with respect to the isotope ratio $R$, that is the most important prognostic quantity for isotope simulations. Furthermore, it retains the properties of the original Bott scheme with respect to positivity (by flux limitation) and mass conservation (owing to the flux formulation of Eq. A1).

In order to examine the performance of this extended scheme, a one-dimensional test is conducted that was designed for testing advection algorithms with respect to the 

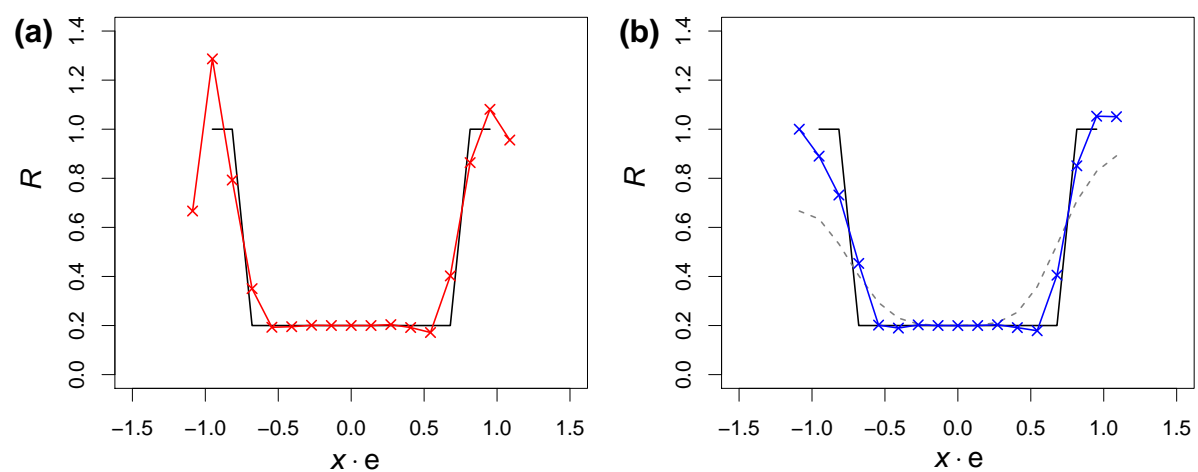

Fig. A1. Results from the one-dimensional advection test after Schär and Smolarkiewicz (1996). The isotope ratio $R$ at time $t=1$ is plotted against the stretched spatial dimension. Solid black lines indicate the analytical solution. The red line in (a) shows the numerical result for both isotopes being transported independently of each other using the original Bott scheme. In (b), the blue line shows the isotope ratio obtained with the modified advection with fourth order accuracy, the gray dashed line indicates the result obtained with zeroth order accuracy. See text for details.

synchronous transport of two tracers by Schär and Smolarkiewicz (1996). The initial moisture fields for this test are defined by

${ }^{1} \psi(x)= \begin{cases}1+x, & -1 \leq x \leq 0 \\ 1, & 0 \leq x \leq 1 \\ 0, & \text { otherwise }\end{cases}$

and

$R(x)= \begin{cases}1, & |x| \geq 0.75 \\ 0.2, & \text { otherwise }\end{cases}$

This moisture is transported by a wind field $u(x)=-x$. For the numerical integration, a grid spacing of $\Delta x=0.05$ and a time step of $\Delta t=0.025$ are used. Figure Ala shows the result of this integration if the original Bott scheme given by Eqs. (A1) to (A4) is used for both the light and the heavy isotopes. The isotope ratio $R(x)$ after 40 time steps is plotted against $x$, scaled with a factor of e, where ${ }^{1} \psi(x)>0$. The solid black line indicates the analytical solution given by Schär and Smolarkiewicz (1996). The numerical result reproduces this analytical solution relatively well at most of the grid points, but there are strong deviations where ${ }^{1} \psi(x)$ is small, in particular around $x \cdot \mathrm{e}=-1$. Similar inconsistencies are typical for many advection schemes (see again Schär and Smolarkiewicz, 1996). The deviations are reduced if the modified advection scheme (Eqs. (A1) and (A5) to (A7)) is used for the heavy isotopes (blue line in Fig. A1b). At the left flank, the numerical solution becomes slightly more diffusive, but the strong overshoot totally disappears. At the right flank, a small overshoot with values of $R$ above 1 can still be observed. The dashed line in Fig. A1b indicates the numerical solution for the modified advection scheme with zeroth order accuracy, i.e., a simple upstream approximation of $R_{i}(\hat{x})$ instead of using Eq. (A5). In this case, which is similar to the approach used by Risi et al. (2010b), there are no inconsistencies, but the numerical diffusion is much larger.
Such diffusion is particularly critical for synoptic-scale simulations that aim at reproducing strong spatial gradients of isotope ratios, e.g., related to a frontal system, as in the present study.

All together, these idealised test simulations show that the modified fourth order Bott advection scheme is well suited for an almost consistent transport of water isotope fields with low numerical diffusion. Note, however, that small inconsistencies may still appear, in contrast to the flux-correction formalism developed by Schär and Smolarkiewicz (1996). This iterative formalism is numerically much too expensive, though, to be used in three-dimensional weather-forecast or climate simulations. The present scheme can thus be regarded as a good compromise between numerical efficiency and the consistency of tracer transport.

Acknowledgements. We are very grateful to Stanley D. Gedzelman and James R. Lawrence for publishing their isotope observations from the 1986 winter storm. We thank Christoph Schär (ETH Zurich) for helpful discussions and three anonymous reviewers for their constructive comments. The National Climatic Data Center at NOAA is acknowledged for giving access to the precipitation time series from the station AVP, MeteoSwiss for providing access to ECMWF analyses. Data analyses and graphics for this study were produced using the software package R.

Edited by: M. K. Dubey

\section{References}

Blossey, P. N., Kuang, Z., and Romps, D. M.: Isotopic composition of water in the tropical tropopause layer in cloud-resolving simulations of an idealized tropical circulation, J. Geophys. Res., 115, D24309, doi:10.1029/2010JD014554, 2010.

Bony, S., Risi, C., and Vimeux, F.: Influence of convective processes on the isotopic composition $\left(\delta^{18} \mathrm{O}\right.$ and 
$\delta \mathrm{D})$ of precipitation and water vapor in the tropics: 1. Radiative-convective equilibrium and Tropical Ocean-Global Atmosphere-Coupled Ocean-Atmosphere Response Experiment (TOGA-COARE) simulations, J. Geophys. Res., 113, D19305, doi:10.1029/2008JD009942, 2008.

Bott, A.: A positive definite advection scheme obtained by nonlinear renormalization of the advective fluxes, Mon. Weather Rev., 117, 1006-1015, 1989.

Celle-Jeanton, H., Gonfiantini, R., Travi, Y., and Sol, B.: Oxygen18 variations of rainwater during precipitation: application of the Rayleigh model to selected rainfalls in Southern France, J. Hydrol., 289, 165-177, doi:10.1016/j.jhydrol.2003.11.017, 2004.

Coplen, T. B., Neiman, P. J., White, A. B., Landwehr, J. M., Ralph, F. M., and Dettinger, M. D.: Extreme changes in stable hydrogen isotopes and precipitation characteristics in a landfalling Pacific storm, Geophys. Res. Lett., 35, L21808, doi:10.1029/2008GL035481, 2008.

Craig, H. and Gordon, L. I.: Deuterium and oxygen 18 variations in the ocean and the marine atmosphere, in: Stable isotopes in oceanographic studies and paleotemperatures, edited by Tongiorgi, E., 9-130, Lab. Geol. Nucl., Pisa, Italy, 1965.

Dansgaard, W.: Stable isotopes in precipitation, Tellus B, 16, 436468, 1964

Dansgaard, W., Johnsen, S. J., Clausen, H. B., Dahl-Jensen, D., Gundestrup, N. S., Hammer, C. U., Hvidberg, C. S., Steffensen, J. P., Sveinbjörnsdottir, A. E., Jouzel, J., and Bond, G.: Evidence for general instability of past climate from a $250-\mathrm{kyr}$ ice-core record, Nature, 364, 218-220, 1993.

Davies, H. C.: A lateral boundary formulation for multi-level prediction models, Q. J. Roy. Meteor. Soc., 102, 405-418, 1976.

Doms, G., Förstner, J., Heise, E., Herzog, H.-J., Raschendorfer, M., Schrodin, R., Reinhardt, T., and Vogel, G.: A description of the nonhydrostatic regional model LM. Part II: Physical parameterization, Deutscher Wetterdienst, Offenbach, Germany, 2005.

Field, R. D., Jones, D. B. A., and Brown, D. P.: Effects of postcondensation exchange on the isotopic composition of water in the atmosphere, J. Geophys. Res., 115, D24305, doi:10.1029/2010JD014334, 2010.

Gat, J. R.: Oxygen and hydrogen isotopes in the hydrological cycle, Annu. Rev. Earth Planet Sci., 24, 225-262, 1996.

Gedzelman, S. D. and Arnold, R.: Modeling the isotopic composition of precipitation, J. Geophys. Res., 99, 10455-10471, 1994.

Gedzelman, S. D. and Lawrence, J. R.: The isotopic composition of precipitation from 2 extratropical cyclones, Mon. Weather Rev., 118, 495-509, 1990.

Hoffmann, G., Werner, M., and Heimann, M.: Water isotope module of the ECHAM atmospheric general circulation model: A study on timescales from days to several years, J. Geophys. Res., 103, 16871-16896, 1998.

Jacob, D., Baerring, L., Christensen, O. B., Christensen, J. H., de Castro, M., Deque, M., Giorgi, F., Hagemann, S., Hirschi, M., Jones, R., Kjellstroem, E., Lenderink, G., Rockel, B., Sanchez, E., Schaer, C., Seneviratne, S., Somot, S., van Ulden, A., and van den Hurk, B.:: An inter-comparison of regional climate models for Europe: Model performance in present-day climate, Clim. Change, 81, 31-52, doi:10.1007/s10584-006-9213-4, 2007.

Joussaume, J., Sadourny, R., and Jouzel, J.: A general circulation model of water isotope cycles in the atmosphere, Nature, 311, 24-29, 1984.
Jouzel, J. and Merlivat, L.: Deuterium and oxygen 18 in precipitation: modeling of the isotope effects during snow formation, J. Geophys. Res., 89, 11749-11757, 1984.

Kessler, E.: On the distribution and continuity of water substance in atmospheric circulations, Meteorol. Monogr., 10, 88 pp., 1969.

Lawrence, J. R., Gedzelman, S. D., White, J. W. C., Smiley, D., and Lazov, P.: Storm trajectories in eastern US D/H isotopic composition of precipitation, Nature, 296, 638-640, 1982.

Liu, Z., Bowen, G. J., and Welker, J. M.: Atmospheric circulation is reflected in precipitation isotope gradients over the conterminous United States, J. Geophys. Res., 115, D22120, doi:10.1029/2010JD014175, 2010.

LeGrande, A. N. and Schmidt, G. A.: Global gridded data set of the oxygen isotopic composition in seawater, Geophys. Res. Lett., 33, L12604, doi:10.1029/2006GL026011, 2006.

Majoube, M.: Fractionnement en oxygén 18 et en deutérium entre l'eau et sa vapeur, J. Chem. Phys., 10, 1423-1436, 1971.

Merlivat, L.: The dependence of bulk evaporation coefficients on air-water interfacial conditions as determined by the isotopic method, J. Geophys. Res., 83, 2977-2980, 1978.

Merlivat, L. and Jouzel, J.: Global climatic interpretation of the deuterium-oxygen 18 relationship for precipitation, J. Geophys. Res., 84, 5029-5033, 1979.

Merlivat, L. and Nief, G.: Fractionnement isotopique lors des changements d'etat solide-vapeur et liquide-vapeur de l'eau a des temperatures inferieures a 0 degrees C, Tellus, 19, 122-127, 1967.

Pfahl, S. and Wernli, H.: Air parcel trajectory analysis of stable isotopes in water vapor in the eastern Mediterranean, J. Geophys. Res., 113, D20104, doi:10.1029/2008JD009839, 2008.

Pfahl, S. and Wernli, H.: Lagrangian simulations of stable isotopes in water vapor - an evaluation of non-equilibrium fractionation in the Craig-Gordon model, J. Geophys. Res., 114, D20108, doi:10.1029/2009JD012054, 2009.

Rindsberger, M., Jaffe, S., Rahamim, S., and Gat, J. R.: Patterns of the isotopic composition of precipitation in time and space: data from the Israeli storm water collection program, Tellus B, 42, 263-271, 1990.

Risi, C., Bony, S., and Vimeux, F.: Influence of convective processes on the isotopic composition $\left(\delta^{18} \mathrm{O}\right.$ and $\left.\delta \mathrm{D}\right)$ of precipitation and water vapor in the tropics: 2. Physical interpretation of the amount effect, J. Geophys. Res., 113, D19306, doi:10.1029/2008JD009943, 2008.

Risi, C., Bony, S., Vimeux, F., Frankenberg, C., Noone, D., and Worden, J.: Understanding the Sahelian water budget through the isotopic composition of water vapor and precipitation, J. Geophys. Res., 115, D24110, doi:10.1029/2010JD014690, 2010 a.

Risi, C., Bony, S., Vimeux, F., and Jouzel, J.: Water-stable isotopes in the LMDZ4 general circultaion model: Model evaluation for present-day and past climates and applications to climatic interpretations of tropical isotopic records, J. Geophys. Res., 115, D12118, doi:10.1029/2009JD013255, 2010b.

Schär, C. and Smolarkiewicz, P. K.: A synchronous and iterative flux-correction formalism for coupled transport equations, J. Comput. Phys., 128, 101-120, 1996.

Schneider, M., Yoshimura, K., Hase, F., and Blumenstock, T.: The ground-based FTIR network's potential for investigating the atmospheric water cycle, Atmos. Chem. Phys., 10, 3427-3442, doi:10.5194/acp-10-3427-2010, 2010. 
Smith, J. A., Ackerman, A. S., Jensen, E. J., and Toon, O. B.: Role of deep convection in establishing the isotopic composition of water vapor in the tropical transition layer, Geophys. Res. Lett., 33, L06812, doi:10.1029/2005GL024078, 2006.

Smith, R. B.: Deuterium in North-Atlantic storm tops, J. Atmos. Sci., 49, 2041-2057, 1992.

Steppeler, J., Doms, G., Schättler, U., Bitzer, H. W., Gassmann, A., Damrath, U., and Gregoric, G.: Meso-gamma scale forecast using the nonhydrostatic model LM, Meteorol. Atmos. Phys., 82, 75-96, 2003.

Stewart, M. K.: Stable isotope fractionation due to evaporation and isotopic exchange of falling waterdrops: applications to atmospheric processes and evaporation of lakes, J. Geophys. Res., 80, 1133-1146, 1975.

Sturm, K., Hoffmann, G., Langmann, B., and Stichler, W.: Simulation of delta O-18 in precipitation by the regional circulation model REMOiso, Hydrol. Process., 19, 3425-3444, 10.1002/hyp.5979, 2005.

Sturm, K., Hoffmann, G., and Langmann, B.: Simulation of the stable water isotopes in precipitation over South America: Comparing regional to global circulation models, J. Clim., 20, 37303750, doi:10.1175/JCLI4194.1, 2007.

Sturm, P. and Knohl, A.: Water vapor $\delta^{2} \mathrm{H}$ and $\delta^{18} \mathrm{O}$ measurements using off-axis integrated cavity output spectroscopy, Atmos. Meas. Tech., 3, 67-77, doi:10.5194/amt-3-67-2010, 2010.
Tiedtke, M.: A comprehensive mass flux scheme for cumulus parameterization in large-scale models, Mon. Weather Rev., 117, 1779-1800, 1989.

Uppala, S. M., Kållberg, P. W., Simmons, A. J., Andrae, U., da Costa Bechtold, V., Fiorino, M., Gibson, J. K., Haseler, J., Hernandez, A., Kelly, G. A., Li, X., Onogi, K., Saarinen, S., Sokka, N., Allan, R. P., Andersson, E., Arpe, K., Balmaseda, M. A., Beljaars, A. C. M., van de Berg, L., Bidlot, J., Bormann, N., Caires, S., Chevallier, F., Dethof, A., Dragosavac, M., Fisher, M., Fuentes, M., Hagemann, S., Hólm, E., Hoskins, B. J., Isaksen, L., Janssen, P. A. E. M., Jenne, R., Mcnally, A. P., Mahfouf, J.-F., Morcrette, J.-J., Rayner, N. A., Saunders, R. W., Simon, P., Sterl, A., Trenberth, K. E., Untch, A., Vasiljevic, D., Viterbo, P., and Woollen, J.: The ERA-40 re-analysis, Q. J. Roy. Meteor. Soc., 131, 2961-3012, 2005.

Wen, X.-F., Zhang, S.-C., Sun, X.-M., Yu, G.-R., and Lee, X.: Water vapor and precipitation isotope ratios in Beijing, China, J. Geophys. Res., 115, D01103, doi:10.1029/2009JD012408, 2010.

Yoshimura, K., Kanamitsu, M., Noone, D., and Oki, T.: Historical isotope simulation using Reanalysis atmospheric data, J. Geophys. Res., 113, D19108, doi:10.1029/2008JD010074, 2008.

Yoshimura, K., Kanamitsu, M., and Dettinger, M.: Regional downscaling for stable water isotopes: A case study of an atmospheric river event, J. Geophys. Res., 115, D18114, doi:10.1029/2010JD014032, 2010. 